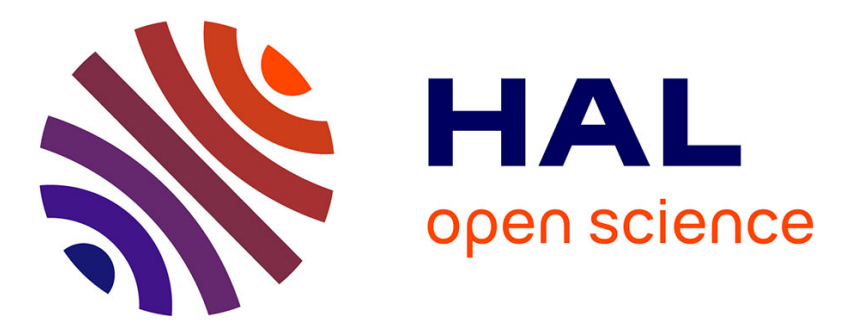

\title{
Exposure Assessment in Millimeter-Wave Reverberation Chamber Using Murine Phantoms
}

\author{
Abdou Khadir Fall, Christophe Lemoine, Philippe Besnier, Ronan Sauleau, \\ Yves Le Dréan, Maxim Zhadobov
}

\section{- To cite this version:}

Abdou Khadir Fall, Christophe Lemoine, Philippe Besnier, Ronan Sauleau, Yves Le Dréan, et al.. Exposure Assessment in Millimeter-Wave Reverberation Chamber Using Murine Phantoms. Bioelectromagnetics, 2020, 41 (2), pp.121-135. 10.1002/bem.22243 . hal-02469494

HAL Id: hal-02469494

https://hal-univ-rennes1.archives-ouvertes.fr/hal-02469494

Submitted on 17 Jul 2020

HAL is a multi-disciplinary open access archive for the deposit and dissemination of scientific research documents, whether they are published or not. The documents may come from teaching and research institutions in France or abroad, or from public or private research centers.
L'archive ouverte pluridisciplinaire HAL, est destinée au dépôt et à la diffusion de documents scientifiques de niveau recherche, publiés ou non, émanant des établissements d'enseignement et de recherche français ou étrangers, des laboratoires publics ou privés. 


\title{
EXPOSURE ASSESSMENT IN MILLIMETER-WAVE REVERBERATION CHAMBER USING MURINE PHANTOMS
}

\author{
Abdou Khadir Fall ${ }^{1}$, Christophe Lemoine ${ }^{1}$, Philippe Besnier ${ }^{1}$, Ronan Sauleau ${ }^{1}$, Y. Le Dréan ${ }^{2}$, and \\ Maxim Zhadobov ${ }^{1}$
}

${ }^{1}$ Univ Rennes, INSA Rennes, CNRS, IETR - UMR CNRS 6164, Rennes, France

${ }^{2}$ Univ Rennes, IRSET - UMR_S 1085, Rennes, France

\author{
Corresponding author \\ Dr. Maxim Zhadobov \\ Institute of Electronics and Telecommunications of Rennes (IETR) \\ University of Rennes 1 \\ 11D, 263 av. du G. Leclerc, 35042 Rennes, France \\ Phone: (+33) 223236706 \\ Email: maxim.zhadobov@univ-rennes1.fr
}

\section{Running title}

Millimeter-wave reverberation chamber

Grant sponsors: French National Research Program for Environmental and Occupational Health (ANSES 2014/2 RF/004) and EU through the European Regional Development Fund (ERDF), Brittany Region, Ministry of Higher Education and Research, Rennes Métropole and Conseil Départemental, through the CPER Project SOPHIE / STIC \& Ondes.

Conflict of interest: none 


\begin{abstract}
This study deals with design and calibration of the first mode-stirred reverberation chamber (RC) in the $60-\mathrm{GHz}$-band adapted for in vivo bioelectromagnetic studies. In addition to the interface for electromagnetic and thermal dosimetry, the interfaces for lighting and ventilation were integrated into the RC walls while preserving acceptable shielding. The $\mathrm{RC}$ with mechanical and electronic steering capabilities is characterized in the 55-65 GHz range. To this end, murine skin-equivalent phantoms of realistic shape were designed and fabricated. Their complex permittivity is within \pm $12 \%$ of the target value of murine skin $(6.19-j 5.81$ at $60 \mathrm{GHz})$. The quality factor of the $\mathrm{RC}$ loaded with an animal cage, bedding litter, and five murine phantoms was found to be $1.2 \times 10^{4}$. The losses inside the RC were analyzed, and it was demonstrated that the main sources of the power dissipation were the phantoms and mice cage. The input power required to reach the average incident power density of $1 \mathrm{~mW} / \mathrm{cm}^{2}$ and $5 \mathrm{~mW} / \mathrm{cm}^{2}$ were found to be $0.23 \mathrm{~W}$ and $1.14 \mathrm{~W}$, respectively. Surface heating of the mice models was measured in the IR range using a specifically designed interface, transparent at IR and opaque at millimeter waves $(\mathrm{mmW})$. Experimental results were compared to an analytical solution of heat transfer equation (HTE) and to full-wave computations. Analytical and numerical results were in very good agreement with measurements (the relative deviation after 90 min of exposure was within 4.2\%). Finally, a parametric study was performed to assess the impact of the thermophysical parameters on the resulting heating.
\end{abstract}

Keywords: millimeter waves; in vivo; infrared imaging; dosimetry; tissue-equivalent models. 


\section{INTRODUCTION}

The number of millimeter-wave $(\mathrm{mmW})$ applications is continuously increasing. In particular, substantial research activities have been focused on development of mmW technologies for wireless high data rate communications in emerging 5G networks, e.g., [MiWaves; MiWEBA; mmMAGIC]. Their near-future deployment raises concerns related to potential health risks [Guraliuc et al., 2017; Wu et al., 2015]. Besides, the Wi-Fi Alliance group created the 802.11ad standard, known as WiGig, for multi-gigabit wireless communications operating in the $60 \mathrm{GHz}$ band [Wi-Fi Alliance, 2016]. Advances in $\mathrm{mmW}$ technologies have also triggered research focused on other potential applications including security [Cotton et al., 2009], medical [Rojavin and Ziskin, 1998; Smulders, 2013; Zhadobov et al., 2015], and military applications.

The ICNIRP guidelines and IEEE standard C95.1 provide recommendations on exposure to electromagnetic waves from $0 \mathrm{~Hz}$ to $300 \mathrm{GHz}$ [ICNIRP, 1998; IEEE Std, 2005]. ICNIRP recommends to limit exposure of the general public in the $60 \mathrm{GHz}$ band to $1 \mathrm{~mW} / \mathrm{cm}^{2}$ under farfield conditions (averaged over $20 \mathrm{~cm}^{2}$ ), but allows for power density levels up to $20 \mathrm{~mW} / \mathrm{cm}^{2}$ for local exposures (averaged over $1 \mathrm{~cm}^{2}$ ). A safety margin is applied to the general public compared to the occupational exposure; for the latter the limit is $5 \mathrm{~mW} / \mathrm{cm}^{2}$ under far-field exposure (averaged over $20 \mathrm{~cm}^{2}$ ) and $100 \mathrm{~mW} / \mathrm{cm}^{2}$ under local exposure (average over $1 \mathrm{~cm}^{2}$ ). A new release of ICNIRP guidelines is expected to be published in the near future. The IEEE Standard C95.1a recommends to limit the incident power density for general public to $1 \mathrm{~mW} / \mathrm{cm}^{2}$ (averaged over $100 \mathrm{~cm}^{2}$ ) and $20 \mathrm{~mW} / \mathrm{cm}^{2}$ (averaged over $1 \mathrm{~cm}^{2}$ ) for far-field and local exposures, respectively. The occupational exposure limit is $10 \mathrm{~mW} / \mathrm{cm}^{2}$ (averaged over $100 \mathrm{~cm}^{2}$ ) and $100 \mathrm{~mW} / \mathrm{cm}^{2}$ 
(averaged over $1 \mathrm{~cm}^{2}$ ) for far-field and local exposures, respectively. Note that this standard was recently updated and the new release was issued in October 2019 [IEEE Std, 2019].

An overview of exposure systems that have been used to study biological impacts of mmW is provided in Zhadobov et al. [2011]. For in vitro exposure at mmW mainly compact anechoic chambers have been used. However, they are of limited interest for in vivo exposure as to accurately control the exposure conditions animals should be kept in a fixed position, which may stress them and reduce the maximum exposure duration. To overcome the limitations of anechoic chamber based exposure systems, mode-stirred reverberation chamber (RC) has been proposed for animal exposure ensuring isotropic exposure regardless the animal posture and location inside the RC. Most of RC-related research applied to bioelectromagnetics has been conducted at frequencies up to $6 \mathrm{GHz}$ [Jung et al., 2007; Jin et al. 2013, Gong et al. 2017; Wu et al., 2010; Aït-Aïssa et al., 2013; Gong et al., 2016; Chakarothai et al, 2014; Shi et al, 2014; Shi et al, 2015].

In 2015, we proposed the first mmW RC covering the $60 \mathrm{GHz}$ band [Fall et al., 2015]. This proof-of-concept prototype was designed for general purpose electromagnetic compatibility testing and was not adapted for animal exposure.

The main purpose of this study is to develop the first RC exposure system adapted for in vivo isotropic exposure of mice in the $60-\mathrm{GHz}$ band. We present the design and calibration procedure of the exposure system based on $\mathrm{RC}$ concept. The $\mathrm{RC}$ is characterized in the $55-65 \mathrm{GHz}$ range in the presence of murine skin-equivalent phantoms. Statistical uncertainties and variability of the power density due to positioning of the phantoms are assessed. The heating due to exposure is measured on the phantom surface using a specific interface, transparent at infrared (IR) frequencies and opaque at $\mathrm{mmW}$, and an IR camera. Other interfaces for air circulation and lighting are integrated into the $\mathrm{RC}$ while preserving acceptable shielding. 


\section{MATERIAL AND METHODS}

\section{Exposure system design}

Figure 1 represents a 3D computer-aided design (CAD) view of the proposed $\mathrm{RC}$ with the inner dimensions of $580 \times 592 \times 595 \mathrm{~mm}^{3}$. The walls were made of $10 \mathrm{~mm}-$ thick aluminum. Two WR-15 open-ended waveguides were used as transmitting and receiving antennas. A metallic mode stirrer connected to a DC motor ensured the random field inside the RC by continuous rotation. It consisted of 8 aluminum blades of $100 \times 90 \times 1 \mathrm{~mm}^{3}$ in different orientations and spread along a metallic cylindrical axis of diameter $10 \mathrm{~mm}$ attached to two sides of the RC. At one of its ends, it was fixed to the DC motor shaft outside the RC, through an interface panel. In addition, an electronic stirring was implemented by the frequency modulation, which can be used independently or together with mechanical stirring.

The exposure system is expected to be located in an air-conditioned room (temperature 20$24{ }^{\circ} \mathrm{C}$; relative humidity $45-65 \%$, air renewal rate $15-20$ times per hour, and light intensity 130 325 lux). The RC was designed to ensure that these conditions were also preserved inside the exposure system. To this end, two low noise $25 \times 25 \mathrm{~mm}^{2}$ fans with a sound level of $31 \mathrm{~dB}$ (the reference acoustic pressure level is fixed at $20 \mu \mathrm{Pa}$ ) and air flow rate of $5 \mathrm{~m}^{3}$ per hour were integrated into the walls (the air inside the $\mathrm{RC}$ renewed about 25 times per hour). The value of the air renewal rate after integration of shielding windows in front of the fans was 16 times per hour.

In order to achieve the targeted light intensity (130-325 lux) inside the RC, 8 windows (100 $\times 100 \mathrm{~mm}^{2}$ ) were integrated into the upper wall. Glass diffusers with a transparency of about $70 \%$ 
in the optical 350-700 $\mathrm{nm}$ range were used to illuminate the $\mathrm{RC}$ and improve the lighting uniformity. Metallic wire grid covered these windows to ensure electromagnetic shielding in the $\mathrm{mmW}$ range. It was made of aluminum with a wire width of $50 \mu \mathrm{m}$ and a period of $254 \mu \mathrm{m}$ leading to a simulated level of the power transmittance of $-26 \mathrm{~dB}$ at $60 \mathrm{GHz}$ (computed using the finite element method implemented in High Frequency Structural Simulator [HFSS]). Aluminum was deposited by sputtering technique and the grid was patterned using photolithography.

Exposure levels and heating of samples under test were monitored using an IR camera following the procedure presented in [Fall et al., 2016]. A specific interface was designed and integrated into the upper wall to ensure simultaneously a high transmittance at IR and acceptable shielding efficiency at $\mathrm{mmW}$. The transmission coefficient measured in the $2.5-5 \mu \mathrm{m}$ IR range was $82 \%$ and shielding efficiency in the $55-65 \mathrm{GHz}$ range was about $-10 \mathrm{~dB}$. Due to integration of all interfaces the measured Q-factor of the RC was reduced by less than $10 \%$.

\section{Experimental set-up}

The fabricated experimental set-up is presented in Figure 2. The RC was made of an aluminum and magnesium alloy (AlMg3.5). We used a tunable Gunn diode-based voltagecontrolled generator (QuinStar, Torrance, CA) operating in the $58-62 \mathrm{GHz}$ range with an output power up to about $4 \mathrm{~W}$. The generator can be operated in swept frequency mode by applying a tuning voltage. The output power level can be adjusted by applying an external DC voltage. Note that, depending on the target application, the system can be used with a different $\mathrm{mmW}$ generator (e.g., a source simulating $5 \mathrm{G} \mathrm{mmW}$ signals). Transmit (Tx) and receiving (Rx) antennas (openended waveguides) were fed by WR-15 waveguides. The power in the RC was measured using an Agilent E4418B power meter (Agilent Technologies, Santa Clara, CA). Note that Rx antennas 
were not located in the middle of the RC since they were also used in presence of the mouse cage during in vivo experiments. Their apertures were located in the statistically homogeneous field zone at $60 \mathrm{GHz}$, which encompasses any point at distance over a quarter wavelength of any obstacle in RC, i.e., $1.25 \mathrm{~mm}$ at $60 \mathrm{GHz}$. It was therefore statistically equivalent to locate $\mathrm{Rx}$ antenna as shown in Figure 2 or in the middle of the RC. This was checked experimentally but not reported for the sake of brevity.

A high-resolution IR camera FLIR SC5000 operating in the 2.5-5 $\mu \mathrm{m}$ spectral range (FLIR Systems, Torcy, France) was used to record the temperature on the phantom. The thermal sensitivity of the camera was $0.025{ }^{\circ} \mathrm{C}$ with a spatial resolution up to $640 \times 512$ pixels. The IR camera was positioned on the top of the RC, and thermal measurements were performed through a specifically designed IR interface (see section Exposure system).

Five murine-equivalent phantoms of realistic shape were placed in a conventional animal cage $\left(290 \times 175 \times 125 \mathrm{~mm}^{3}\right)$ filled with $30 \mathrm{~g}$ of bedding litter. The cage was installed on two aluminum bars mounted in the center of the RC inner volume. Electromagnetic field in the volume of the chamber may be considered as statistically homogeneous at distances greater than a quarter wavelength of any obstacle in RC, i.e., $1.25 \mathrm{~mm}$ at $60 \mathrm{GHz}$. Their impact on the field distribution in the cage was negligible. Therefore, rather than hanging the cage, we opted for a more secured and fixed placement of the cage with animals during in vivo exposure experiments.

\section{Phantoms}


The effective complex permittivity of murine skin at mmW was reported by Alekseev et al. [2008]. Up to roughly $100 \mathrm{GHz}$, the complex permittivity of skin is described by the Debye model with single relaxation time:

$$
\varepsilon^{*}=\varepsilon_{\infty}+\frac{\Delta \varepsilon}{1+j 2 \pi f \tau}+\frac{\sigma_{i}}{j 2 \pi f \varepsilon_{0}}
$$

where $f$ is the frequency, $\Delta \varepsilon=16.10$ the magnitude of dispersion, $\tau=6.9 \times 10^{-12} \mathrm{~s}$ the relaxation time, $\varepsilon_{\infty}=4.12$ the optical relative permittivity, and $\sigma_{i}=1.4 \mathrm{~S} / \mathrm{m}$ the ionic conductivity. At 60 $\mathrm{GHz}$, this model yields $\varepsilon^{*}=6.19-j 5.81$.

Experimental human skin-equivalent models reported at mmW so far are semi-solid waterbased phantoms [Chahat et al., 2011; Aminzadeh et al., 2014; Leduc at al., 2017]. Their complex permittivity is mainly adjusted by concentration of the polyethylene powder. We used a similar approach to design a murine skin phantom; its ingredients are listed in Table 1.

Fabrication procedure of the murine-equivalent phantom of a realistic shape and dimensions consists in three consecutive steps. First, we used a 3D printer to create a plastic murine model. A generic CAD file of a mouse was scaled by a factor of 0.9 and used to print the plastic murine model. Second, the printed plastic model served for manufacturing a silicon mold. Third, the mold was used to fabricate a semi-solid phantom (Fig. 3) as described in [Chahat et al., 2011]. The mass of the fabricated phantom was approximatively $230 \mathrm{~g}$. Note that this homogeneous phantom does model the structure of the skin, and in particular the stratum corneum, which was shown to contribute to the reflection coefficient of the skin [Neufeld et al, 2018; Ziskin et al, 2018].

A coaxial probe (DAK, Speag, Zurich, Switzerland) connected to a vector network analyzer (ZVA 67, Rohde \& Schwartz, Munich, Germany) was used to measure the complex permittivity of the phantom at 55-65 GHz (Fig. 4). The calibration of the probe was performed 
using open, short and dielectric load according to the DAK Professional Handbook. The phantom complex permittivity was within $\pm 12 \%$ of the target murine skin permittivity $( \pm 0.4 \%$ for the real part and $\pm 12 \%$ for the imaginary part). This corresponded to a variation of $2 \%$ and $8 \%$ in terms of the absorbed power and skin depth in the $55-65 \mathrm{GHz}$ range, respectively.

For validation of the methodology we also used as a reference an agar phantom composed of distilled water and $4 \%$ agar. The electromagnetic properties of a $4 \%$ agar phantom are well known and its fabrication is straightforward. Due to the high water concentration, the permittivity of this phantom is close to that of free water $\left(\varepsilon^{*}=11.9-j 19.5\right.$ at $\left.60 \mathrm{GHz}\right)$ [Ellison, 2007; Chahat et al., 2012].

Table 2 reports the thermophysical properties of the murine-equivalent phantom, waterequivalent phantom, and murine skin. The thermal properties of the proposed murine equivalent phantom with a polyethylene concentration of $30 \%$ were derived by extrapolation from data for $20 \%$ and $25 \%$ polyethylene phantoms [Chahat et al., 2012]. The thermal conductivity of waterequivalent phantom was investigated by Zhang et al. [2010]. Murine skin thermal conductivity and heat capacity were provided by Gong et al. [2016]. The thermal conductivity of the murineequivalent phantom was higher compared to the one of in vivo murine skin (the difference is 22.9 $\%$ ). However, the specific heat capacities were almost the same; the deviation was less than $1 \%$.

\section{Temperature distribution on phantoms}

It was demonstrated that the surface heating of a lossy object placed inside a RC can be predicted from the average power density and vice versa [Fall et al., 2016]. This is achieved by solving the 3D bioheat transfer equation [Foster, 1978]: 


$$
\frac{\rho C \partial T}{k_{t} \partial t}=\frac{\partial^{2} T}{\partial x^{2}}+\frac{\partial^{2} T}{\partial y^{2}}+\frac{\partial^{2} T}{\partial z^{2}}-\frac{V_{s}}{k_{t}}\left(T-T_{b}\right)+\frac{q(x, y, z, t)}{k_{t}}
$$

where $T$ is the temperature at the phantom surface $\left[{ }^{\circ} \mathrm{C}\right], T_{b}$ is the blood temperature, $\rho$ its mass density $\left[\mathrm{kg} / \mathrm{m}^{3}\right], C$ its specific heat $[\mathrm{J} / \mathrm{kg} \cdot \mathrm{K}]$, and $k_{\mathrm{t}}$ its thermal conductivity $[\mathrm{W} / \mathrm{m} \cdot \mathrm{K}], \mathrm{V}_{\mathrm{s}}=f_{\mathrm{b}} \cdot \rho_{\mathrm{b}} \cdot \mathrm{C}_{\mathrm{b}}$ $\left[\mathrm{W} / \mathrm{K} \cdot \mathrm{m}^{3}\right]$ where $f_{\mathrm{b}}$ is the specific blood flow rate (zero for a homogeneous phantom), $\rho_{\mathrm{b}}$ and $C_{\mathrm{b}}$ are the density and specific heat of blood, respectively. The source term $q(x, y, z, t)$ is the heat deposition induced by $\mathrm{mmW}\left(\mathrm{W} / \mathrm{m}^{3}\right)$. Heat exchanged between the phantom and air can be described by the following boundary condition:

$$
k_{t} \frac{\partial T}{\partial x, y, z}=h\left(T-T_{\text {ext }}\right) \forall x, y, z \in \partial \Omega_{\mathrm{x}, \mathrm{y}, \mathrm{z}}
$$

where $h$ is the phantom heat transfer coefficient $\left[\mathrm{W} / \mathrm{m}^{2} \cdot \mathrm{K}\right]$, incorporating radiation, evaporation and convection effects. $T_{\text {ext }}$ is the ambient temperature $\left[{ }^{\circ} \mathrm{C}\right]$ and $\partial \Omega_{\mathrm{x}, \mathrm{y}, \mathrm{z}}$ defines the boundary surface of the phantom.

In an ideal overmoded cavity (as described by Hill [1998]), the dissipated power in a lossy object is expressed as a function of the average power density, penetration depth and average plane-wave power transmission coefficient.

\section{Power density inside RC}

Around $60 \mathrm{GHz}$, the incident power density is used as a dosimetric quantity as the penetration depth of the electromagnetic field inside high water content tissues is shallow [ICNIRP, 1998]. The average power density inside the RC $S_{\mathrm{c}}$ is related to the power received by an antenna placed inside the RC and the antenna effective area $\lambda^{2} / 8 \pi$ as [Hill et al., 1994]: 


$$
S_{c}=\frac{8 \pi}{\lambda^{2}} \times P_{r},
$$

where $\lambda$ is the free-space wavelength. The $Q$-factor, one of the main characteristics of a $\mathrm{RC}$, is related to the power received by an antenna $P_{r}$ as [Hill et al., 1994]:

$$
Q=\frac{16 \pi^{2} V}{\lambda^{3}} \times\left(\frac{P_{r}}{P_{t}}\right)
$$

where $V$ is the RC inner volume, $P_{r} / P_{t}$ represents the ratio of the received power to the transmitted power (input power) over $N$ positions of the stirrer. Brackets $<>$ stand for averaging over the positions of the stirrer. Thus the average power density can be expressed as:

$$
S_{c}=\frac{\lambda \times Q \times P_{t}}{2 \pi V}
$$

In an ideal $\mathrm{RC}$, the electromagnetic field is the combination of various independent states obtained though mechanical and frequency stirring. As a result, in a RC, the electromagnetic field tends towards statistically uniform and isotropic. It is described by its statistical distribution and moments. Using the generalized extreme value distribution [Orjubin, 2007], we estimated the ratio of $99.99 \%$ quantile of the power density and mean power density to about $8.5 \mathrm{~dB}$.

The calibration of the power density $S_{c}$, estimated from equation (6), was performed through the comparison of the measured temperature dynamics on the phantom recorded by the IR camera and analytical or numerical solution of the bioheat transfer equation (2) with boundary conditions given in equation (3). 
First, the calibration was performed for a water-equivalent phantom of parallelepiped shape to analytically analyze modification of the $Q$-factor and adjust the transmitted power to reach the target average power density using equation (6). This procedure allowed us to compare the experimental temperature dynamics with analytical calculation. The latter refers to a solution of the bioheat transfer equation, where the calibrated $S_{c}$ enters the source term $q$ of equation (2) [Fall et al., 2016]. The calculated and measured temperature dynamics were compared accounting for a possible uncertainty in analytical formulation or phantom fabrication.

Second, murine phantoms were used. This step was required to calibrate the power density and check temperature dynamics with realistic phantoms simulating the exposed animals. For such a complex geometry neither the modification of the $Q$-factor nor the solution of the bioheat transfer equation finds an analytical solution. Therefore we started by measuring the $Q$-factor of the RC loaded with murine phantoms to estimate the average power density. Then the bioheat equation was solved numerically with the finite difference time domain (FDTD) technique implemented in Computer Simulation Technology (CST, Darmstadt, Germany) thermal solver. The difference between measured and computed temperature dynamics provides the calibration factor.

\section{RESULTS}

\section{Statistical characterization of exposure environment}

This section reports the results of the statistical characterization of the electromagnetic field inside the RC. The statistical properties of the electric and magnetic fields in an ideal RC are those of a perfect diffuse field or Gaussian random field as derived by Hill [1998]. An ideal RC is the 
result of an adequate combination of mode density according the frequency of operation and modal overlapping which involves some losses. The presence of additional lossy objects modifies the RC performance [Holloway et al., 2006]. Hereafter we analyze the statistical properties of the RC in presence of the lossy murine phantoms, animal cage and bedding litter. Results of statistical distributions are presented for a set of data, which is homogeneous to the square modulus of the electric-field strength. From complex scattering parameters measured with a vector network analyzer, we also retrieved data for testing Gaussian distributions of real and imaginary parts of electric-field strength and for testing Rayleigh distribution of the modulus of electric-field strength at several positions of Rx antenna. These tests confirmed the hypothesis of Gaussian and Rayleigh distribution, respectively. Moreover, they also confirmed that the electric field is statistically uniform within the $\mathrm{RC}$ volume. We provide the final synthesis of the statistics of the square modulus the square electric field, which follows an exponential distribution if the modulus of the electric field follows a Rayleigh distribution

A vector network analyzer (ZVA 67, Rohde \& Schwartz, Munich, Germany) is used to measure the transfer function between two locations in the RC volume. The vector network analyzer is used due to its high dynamic range instead of the V-band power generator and power meter. The calibration was performed using a standard V-band waveguide calibration kit (open, short, and load). Scattering parameters are measured in the $55-65 \mathrm{GHz}$ range with a frequency resolution of $10 \mathrm{MHz}$ for $N=100$ positions of the mechanical stirrer. The measured data are spread over separate series composed of S-parameters measured in 20 sub-bandwidths of $500 \mathrm{MHz}$ and 100 positions of the mechanical stirrer. This leads to 20 series of 5000 individual measurements ( $P=50$ frequencies $\times N=100$ positions $).$ 
It is well known that, in an ideal overmoded RC, the real and imaginary parts of each rectangular component of the electric field follow a Gaussian distribution [Hill, 1998]. Therefore the square modulus of each rectangular component is exponentially distributed. Some authors [Holloway et al., 2006b; Lemoine et al., 2007] showed that the stirred component of the scattering component $S_{21}$ follows the same statistics as a rectangular component of the electric field. As a result, the square modulus of the complex transfer function is exponentially distributed. This stirred transfer function of the RC channel when using two antennas becomes:

$$
|H|=\frac{\left|S_{21}\right|^{2}-\left|\left\langle S_{21}\right\rangle\right|^{2}}{\left(1-\left|\left\langle S_{11}\right\rangle\right|^{2}\right) \times\left(1-\left|\left\langle S_{22}\right\rangle\right|^{2}\right) \eta_{e} \eta_{r}}
$$

where $\eta_{\mathrm{e}}, \eta_{r}$ denote the efficiency of the emitting and receiving open-ended waveguide, respectively.

Prior to the statistical test, the first-order autocorrelation function (FOAF) is calculated from $|H|$ to check the non-correlation between the stirrer positions. The resulting values of the FOAF is averaged over the $P=50$ samples of $N=100$ stirrer positions. The results presented in Figure 5 show that the stirrer positions are uncorrelated (FOAF almost 0) [Lemoine et al., 2008].

The Anderson-Darling (AD) goodness-of-fit test (GoF) [Lemoine et al., 2007] is used here to test if the modulus transfer function $|H|$ is exponentially distributed. The statistical test consists in accepting or rejecting the hypothesis $H_{0}$, which claims that the experimental samples are from the assumed distribution. The AD GoF test is applied at each frequency to a sample made of measurements on $N=100$ positions of the stirrer (mode tune), $P=50 \mathrm{GoF}$ tests are performed over a bandwidth of $500 \mathrm{MHz}$. The ratio between the number of rejected tests and the total number of tests is called the rejection rate (expressed as percentage). Figure 6 represents the rejection rate calculated for 20 series uniformly distributed in the $55-65 \mathrm{GHz}$ range. The hypothesis $H_{0}$ of 
exponential distribution is accepted according to the test since the rejection rate is rather small, i.e around $10 \%$ in average, slightly above the prescribed confidence interval (5\%). The estimation of the standard deviation normalized to the mean (Fig. 7) is also in agreement with the AD GoF test; it is very close to 1 as expected for such a distribution. Thus, the exposure system behavior is consistent with the statistical description of Hill [1998].

\section{Power dissipation inside $R C$}

The quality factor is a key parameter to evaluate the distribution of the power dissipated inside the exposure system. Power dissipated in the walls, lossy objects and antennas are included in the quality factor. The composite quality factor of the exposure system loaded with the phantoms, the bedding litter and the animal plastic cage is expressed as [Hill, 1994]:

$$
Q^{-1}=Q_{\text {wall }}^{-1}+Q_{\text {phantom }}^{-1}+Q_{\text {litter }}^{-1}+Q_{\text {cage }}^{-1}
$$

In equation (8), it is assumed that the individual loss mechanisms are independent. Besides, the $Q$ factor associated to each object can be related to the steady state energy in the chamber $U_{s}[\mathrm{~J}]$, the pulsation $\omega[\mathrm{rad} / \mathrm{s}]$ and the dissipated power $P_{\mathrm{d}}[\mathrm{W}]$ in the object:

$$
Q=\omega \frac{U_{s}}{P_{d}}
$$

In practice, the experimental composite $Q$-factor of the $\mathrm{RC}$ is estimated using [Hill, 1994]:

$$
Q=\frac{16 \pi^{2} V}{\lambda^{3}} \times\langle|H|\rangle
$$

where $\lambda$ is the wavelength, $V$ the inner volume of the RC and $|H|$ denotes the transfer function of the RC channel. 
The composite quality factors of each loss mechanism averaged over a bandwidth of 500 $\mathrm{MHz}$ are plotted in Figure 8. Cumulative losses due to the phantoms, animal cage and bedding litter strongly impact the RC quality factor (it is reduced by a factor close to 6). The impact of the presence of the phantoms is roughly the same as the animal cage, and is slightly higher than that of the bedding litter. From the $Q$-factor, the ratio of power dissipated in each medium can be evaluated. Results are summarized in Table 3.

The variability of the quality factor and the power dissipated in the phantoms were investigated with respect to the positions of the phantoms inside the animal cage. Figure 9 shows the arrangement of the phantoms in five configurations. The positions of the phantoms are set in order to depict the extreme cases. As expected, the quality factor associated with the case $\mathrm{C}$ gives the lowest estimate (Fig. 10). In this configuration, the masking effect between the phantoms is the smallest. The cases A and E give the upper bound of the estimated quality factor. The proximity of the phantoms leads to an important masking effect and consequently reduction of the total power dissipated in the phantoms. The difference between the upper and lower bound of the quality factor at $60 \mathrm{GHz}$ is about $6.3 \%$ (in average $7.3 \%$ in the $55-65 \mathrm{GHz}$ range).

\section{Validation using water-equivalent phantom}

As described above, the power density in the RC can be derived from the quality factor using equation (6). The aim of this section is to check whether the power density estimated from (6) is consistent with that derived from temperature rise measurements. The approach consists in comparing the temperature gradient measured using the IR camera on a phantom to the solution of the 3D heat equation. The exposure system is loaded with a parallelepiped $9.9 \times 9.9 \times 1.4 \mathrm{~cm}^{3}$ water-equivalent phantom. The phantom is placed on a plastic grid with $0.2 \mathrm{~mm}$ linewidth installed 
on the test bench, in front of the camera. Figure 11 shows the temperature increment on the waterequivalent phantom after $800 \mathrm{~s}$ of exposure.

To compare the measured and calculated temperature increase, the temperature is averaged over the central area on one side of the phantom far from the edges. They are plotted in Figure 12. A very good agreement is observed between analytical calculation and measured results (the deviation is about $3.77 \%$ and $2.59 \%$ for input powers of $3.59 \mathrm{~W}$ and $2.85 \mathrm{~W}$, respectively).

These results confirm that the relationship between the Q-factor of the chamber, that of this simple phantom, and the thermal model is well established under the hypothesis of an ideal random field. As a consequence the temperature dynamics is well predicted and controlled.

\section{Temperature distribution on murine phantoms}

In this section, the temperature rise distribution on the phantoms are determined based on IR thermometry and numerical simulations using the thermal module of CST. We analyze the temperature rise induced by exposure to $60-\mathrm{GHz}$ radiation with the incident power densities of 1 $\mathrm{mW} / \mathrm{cm}^{2}$ and $5 \mathrm{~mW} / \mathrm{cm}^{2}$.

The transmitted power within the RC (loaded with the five phantoms) to ensure average incident power densities of $1 \mathrm{~mW} / \mathrm{cm}^{2}$ and $5 \mathrm{~mW} / \mathrm{cm}^{2}$ is 230 and $1140 \mathrm{~mW}$, respectively (Equation 6). This estimation accounts for the open-ended waveguide mismatch $\left(1-|\Gamma|^{2}=0.95\right)$ and efficiency $\left(\eta_{\mathrm{e}}=0.95\right)$, as well as for the quality factor of the RC loaded with the five phantoms, bedding liter and animal cage $\left(Q=1.2 \times 10^{4}\right)$. From the ratio of dissipated power $(27 \%)$ in the five identical murine phantoms (Table 3), the average power dissipated in each phantom is estimated to 12.2 $\mathrm{mW}$ and $61.4 \mathrm{~mW}$, respectively. 
In simulations, the dissipated power in murine phantom computed form quality factor measurement is used as a heat source in thermal simulations. The dissipated power is assumed to be uniformly distributed over the phantom surface. In the thermal modeling, we used the thermophysical properties of the murine phantoms reported in Table 2. The radiative heat transfer coefficient is estimated using the Stephan-Boltzmann law $h_{\mathrm{r}}=5.47 \pm 0.3 \mathrm{~W} /\left(\mathrm{m}^{2} \cdot \mathrm{K}\right)$, where the phantom emissivity is assumed to be $e=0.95 \pm 0.05$ [Leduc et al., 2017; Fall et al., 2016]. The convective heat transfer $h_{\mathrm{c}}$ in the exposure chamber is mainly restricted to natural convection; air motion in the $\mathrm{RC}$ is considered to be negligible when the fans are off. The natural heat convection coefficient depends on the difference between the phantom and environmental temperature. By assuming that the phantom temperature rise is between $1{ }^{\circ} \mathrm{C}$ and $3{ }^{\circ} \mathrm{C}, h_{\mathrm{c}}$ can be predicted from [Wissler, 1961] as 3.3 to $4.4 \mathrm{~W} /\left(\mathrm{m}^{2} \cdot \mathrm{K}\right)$.

Thermal measurements were performed for the exposure duration of $5400 \mathrm{~s}$ with $1 \mathrm{~s}$ resolution. Detailed methodology of the temperature monitoring on semi-solid phantoms during $\mathrm{mmW}$ exposure is presented in [Leduc at al., 2017]. Five murine-equivalent phantoms were placed in the animal cage (configuration B, Fig. 9). The mechanical stirrer was rotating continuously (4 tr/min) combined with the frequency stirring with 30 excitation frequencies distributed in $58.65-$ $59.15 \mathrm{GHz}$ range.

Figure 13 represents temperature increment on two murine-equivalent phantoms after 5400 $\mathrm{s}$ of exposure. The temperature rise distributions on the two phantoms present a similar trend. The discrepancies and asymmetric temperature distribution are mainly due to imperfections of the experimental phantom fabrication and reflections of the IR radiation inside the RC. The mean values of the temperature rise are $2.30^{\circ} \mathrm{C}$ and $2.32{ }^{\circ} \mathrm{C}$, while the standard deviation (square root of the variance) are $0.16{ }^{\circ} \mathrm{C}$ and $0.22{ }^{\circ} \mathrm{C}$. Note that temperature on the muzzle, ears and back of 
the phantom are higher than in other parts of the phantom due to a high surface/volume ratio resulting in a local increase of the power density in the near-surface regions.

The computed temperature profile on the murine phantom under a plane wave spectrum illumination (Fig. 14) is in agreement with measurements. A plane wave spectrum model is an equivalent representation of the random superposition of many modes mimicking the ideal random field of RC. The incident field is equivalent to the superposition of many plane waves of the same field amplitude with random polarization and angle of incidence, having a uniform distribution. Therefore, the source term of the bioheat transfer equation is related to the average electromagnetic power density in RC according to [Fall et al., 2016.]. Figure 15 shows the heat dynamics for the temperature averaged over the surface limited by a rectangle indicated in Figure 13. Error bars on the simulated curve denote the temperature uncertainties resulting from the statistical estimation of the dissipated power ratio (the $95 \%$ confidence interval associated to the quality factor estimation). Results show good agreement between the simulated and measured heating; the relative deviation is within $3.7 \%$. Deviations for short durations can be attributed to the sensitivity of the temperature measurement, which is of the order of $0.1-0.2^{\circ} \mathrm{C}$, and therefore the results for the first minutes of exposure are less accurate compared to longer exposure durations. The temperature rise dynamics for the murine phantom and murine skin (Table 2) are compared in Figure 16. The results suggest that after $5400 \mathrm{~s}$ of exposure use of the murine phantom results in overestimation of heating by about $10 \%$ compared to the murine skin.

Note that the presented thermal results for artificial models do not account for the heat transfer related to sweating, a cooling mechanism in in vivo models. However, the proposed methodology for determining $S_{c}$ and measured temperature rise remains valid as it is independent on the heat transfer coefficient and other parameters used in analytical and numerical models. 


\section{Parametric study}

In this section, we discuss the variations of the temperature rise on the phantom surface due to the uncertainties of the power density, heat transfer coefficient $h$, thermal conductivity $k_{\mathrm{t}}$ and specific heat $C$. Variations of the average power density can be associated to uncertainties on the quality factor. Uncertainty of the volume $V$, frequency $f$ and input power $P_{\mathrm{t}}$ are negligible compared the quality factor statistical uncertainty. The average quality factor is estimated over $N$ $=100$ positions of the stirrer and $P=50$ frequency in each $500 \mathrm{MHz}$ band. One can demonstrate using the central limit theorem that the estimated mean value for the quality factor $\hat{\mu}_{Q}$ is normally distributed with the standard deviation [Kostas et al., 1991]:

$$
\sigma_{\hat{\mu}_{Q}}=\frac{\sigma_{Q}}{\sqrt{N \times P}}
$$

where $\sigma_{Q}$ is the standard deviation of the exponential distribution associated to the modulus of $\mathrm{H}$. The confidence interval associated to the mean value estimation can be deduced from normal distribution as

$$
I=\hat{\mu}_{Q} \pm \frac{k \times \sigma_{Q}}{\sqrt{N \times P}}
$$

where $k$ determines the confidence. For example $a$ confidence of $97.5 \%$ corresponds to $k=1.96$. The normalization of equation (12) enables to calculate the relative variation around the mean value estimation given by 


$$
I_{n}=1 \pm \frac{k}{\sqrt{N \times P}} \times \frac{\sigma_{Q}}{\mu_{Q}} \approx 1 \pm \frac{k}{\sqrt{N \times P}}
$$

The error over the average quality factor estimation is $\pm 2.8 \%$ with $95 \%$ of confidence level.

As discussed previously, the variations of the radiative heat transfer coefficient are estimated to $h_{\mathrm{r}}=5.47 \pm 0.3 \mathrm{~W} /\left(\mathrm{m}^{2} \cdot \mathrm{K}\right)$. With regards to the convective heat coefficient, it varies between 3.3 and $4.4 \mathrm{~W} /\left(\mathrm{m}^{2} \cdot \mathrm{K}\right)$. The thermal conductivity and the specific heat of the $30 \%$ polyethylene phantom are derived from linear extrapolation from data for $25 \%$-polyethylene phantom. We assumed that $k_{\mathrm{t}}$ and $C$ are varying in a $\pm 10 \%$ range, although the actual uncertainty on these parameters is expected to be lower. The uncertainty on the temperature rise of each variable is assessed through simulations with CST. Results are reported in Table 4 for $5400 \mathrm{~s}$ of exposure. The temperature change due to the power density variability is $\pm 3.3 \%$, which is nearly the $95 \%$ confidence interval on the average power density estimation $( \pm 2.8)$. This uncertainty can be reduced in future experiments by increasing the number of independent realizations used to estimate the quality factor.

The specific heat has a strong impact on heating $(10 \%)$ in contrast to the conductivity (less than $2 \%$ ). These results show that an accurate quantification of the phantom specific heat is of importance. With regard to the heat transfer radiation, its range of variations strongly depends on environmental conditions, including temperature and velocity.

\section{CONCLUSION}


This paper describes the design and calibration of a reverberation chamber developed as an exposure system for in vivo studies on mice in the $60-\mathrm{GHz}$ band. In addition to the interface for electromagnetic and thermal dosimetry, the interfaces for lighting and ventilation were integrated into the RC walls while preserving acceptable shielding.

To characterize the electromagnetic behavior of the system, the complex power transfer function is retrieved from scattering parameter measured between two WR-15 opened ended waveguides used as transmitting and receiving antennas in the RC loaded with five murine phantoms, animal cage, and bedding litter. The murine-equivalent phantoms were specifically designed for this study, for the first time in the $60 \mathrm{GHz}$ band. Results of the Anderson Darling goodness-of-fit test and empirical estimation of the standard deviation to mean ratio confirm the exponential distribution hypothesis of the modulus transfer function. This demonstrates that the loaded RC provides a nearly-ideal random Gaussian distributed field.

The calibration procedure of the power density was based on the quality factor, which was estimated to $1.2 \times 10^{4}$ at $60 \mathrm{GHz}$ for the $\mathrm{RC}$ loaded with a mice cage, litter, and five phantoms. The main sources of the power dissipation in the chamber were the mice cage and murine phantoms. In particular, roughly $27 \%$ of the input power is dissipated in phantoms when the RC is loaded with five mice models. The relationships between, the transmitted power in the RC, average power density, composite quality factor and thermal measurements were investigated. The transmitted power within the RC (loaded with the five phantoms) to ensure average incident power densities of $1 \mathrm{~mW} / \mathrm{cm}^{2}$ and $5 \mathrm{~mW} / \mathrm{cm}^{2}$ was found to be 0.23 and $1.14 \mathrm{~W}$, respectively.

Surface heating of the mice models was measured in the IR range using a specifically designed interface, transparent at IR and opaque at $\mathrm{mmW}$. Experimental results were compared to an analytical solution of heat transfer equation (HTE) and to full-wave computations. Analytical 
and numerical results were in a very good agreement with measurements (the relative deviation after 90 min of exposure was within 4.2\%). Finally, a parametric study was performed to assess the impact of the thermophysical parameters on the resulting heating.

The exposure system and methodology reported in this paper can be applied to study potential modifications induced in mice models after $\mathrm{mmW}$ exposure. This type of studies are of importance due to near future integration of $\mathrm{mmW}$ technologies in $5 \mathrm{G}$ as well as due to increasing interest in biomedical applications of mmW [Zhadobov et al, 2015; Orlacchio et al, 2019].

\section{ACKNOWLEDGEMENT}

We acknowledge Frédéric Percevault and Dr François Ferrière for their advices.

\section{REFERENCES}

Aït-Aïssa S, De Gannes FP, Taxile M, Billaudel B, Hurtier A, Hurtier A, Haro E, Ruffie G, Athané A, Veyret B, Lagroye I. 2013. In situ expression of heat-shock proteins and 3-nitrotyrosine in brains of young rats exposed to a WiFi signal in utero and in early life. Rad Res 179(6):707-716.

Alekseev SI, Gordiienko OV, Ziskin MC. 2008. Reflection and penetration depth of millimeter waves in murine skin. Bioelectromagnetics 29(5):340-344.

Aminzadeh R, Saviz M, Shishegar AA. 2014. Theoretical and experimental broadband tissueequivalent phantoms at microwave and millimetre-wave frequencies. Electron Lett 50(8):618-620. 
Bellossi A, Dubost G, Moulinoux JP, Himdi M, Ruelloux M, Rocher C. 2000. Biological effects of millimeter wave irradiation on mice-preliminary results. IEEE Trans Microwave Theory Tech 48(11):2104-2110.

Chahat N, Zhadobov M, Augustine R, Sauleau R. 2011. Human skin permittivity models for millimetre-wave range. Electron Lett 47(7):427-428.

Chahat N, Zhadobov M, Sauleau R, Alekseev SI. 2012. New method for determining dielectric properties of skin and phantoms at millimeter waves based on heating kinetics. IEEE Trans Microwave Theory Tech 60(3):827-832.

Chakarothai J, Wang J, Fujiwara O, Wake K, Watanabe S. 2014. A hybrid MoM/FDTD method for dosimetry of small animal in reverberation chamber. IEEE Trans Electromag Compat 56(3):549-558.

Cotton, SL, Scanlon WG, Madahar BK. 2009. Millimeter-wave soldier-to-soldier communications for covert battlefield operations. IEEE Com Magazine 47(10):72-81.

Ellison WJ. 2007. Permittivity of pure water, at standard atmospheric pressure, over the frequency range 0-25 THz and the temperature range 0-100 8 C. J Phys Chem Ref Data 36(1):1-18.

Fall AK, Besnier P, Lemoine C, Zhadobov M, Sauleau R. 2015. Design and experimental validation of a mode-stirred reverberation chamber at millimeter waves. IEEE Trans Electromag Compat 57(1):12-21.

Fall, AK, Besnier P, Lemoine C, Zhadobov M, Sauleau R. 2016. Experimental dosimetry in a mode-stirred reverberation chamber in the 60-GHz band. IEEE Trans Electromag Compat 58(4):981-992.

Foster KR, Kritikos HN, Schwan HP. 1978. Effect of surface cooling and blood flow on the microwave heating of tissue. IEEE Trans Biomed Eng 25(3):313-316. 
Gong Y, Capstick M, Tillmann T, Dasenbrock C, Samaras T, Kuster N. 2016. Desktop exposure system and dosimetry for small scale in vivo radiofrequency exposure experiments. Bioelectromagnetics 37(1):49-61.

Gong Y, Capstick MH, Kuehn S, Wilson PF, Ladbury JM, Koepke G, McCormick DL, Melnick RL, Kuster N. 2017. Life-time dosimetric assessment for mice and rats exposed in reverberation chambers for the two-year NTP cancer bioassay study on cell phone radiation. IEEE Trans Electromag Compat 59(6):1798-1808.

Guraliuc A, Zhadobov M, Sauleau R, Marnat L, Dussopt L. 2017. Near-field user exposure in forthcoming 5G scenarios in the 60-GHz band. IEEE Trans Antennas Propag 65(12):66066615.

Haas AJ, Le Page Y, Zhadobov M, Sauleau R, Le Dréan Y. 2016. Effects of 60-GHz millimeter waves on neurite outgrowth in PC12 cells using high content screening. Neurosci Lett 618:58-65.

Habauzit D, Le Quément C, Zhadobov M, Martin C, Aubry M, Sauleau R, Le Dréan Y. 2014. Transcriptome analysis reveals the contribution of thermal and the specific effects in cellular response to millimeter wave exposure. PLoS One 9(10):e109435.

Hill DA, Ma MT, Ondrejka AR, Riddle BF, Crawford ML, Johnk RT. 1994. Aperture excitation of electrically large, lossy cavities. IEEE Trans Electromagnetic Compat 36(3):169-178.

Hill DA. 1998. Plane wave integral representation for fields in reverberation chambers. IEEE Trans Electromagnetic Compat 40(3):209-217.

Holloway CL, Hill DA, Ladbury JM, Koepke G. 2006. Requirements for an effective reverberation chamber: Unloaded or loaded. IEEE Trans Electromag Compat 48(1):187-194. 
Holloway CL, Hill DA, Ladbury JM, Wilson PF, Koepke G, Coder J. 2006. On the use of reverberation chambers to simulate a Rician radio environment for the testing of wireless devices. IEEE Trans Antennas Propag 54(11):3167-3177.

ICNIRP. 1998. Guidelines for limiting exposure to time-varying electric, magnetic, and electromagnetic fields (up to $300 \mathrm{GHz}$ ). Health Phys 74(4):494-522.

IEEE Std C95.1-2005. 2005. IEEE standard for safety levels with respect to human exposure to radio frequency electromagnetic fields, $3 \mathrm{kHz}$ to $300 \mathrm{GHz}$. International Committee on Electromagnetic Safety, The Institute of Electrical and Electronics Engineers. New York, USA.

IEEE Std C95.1-2019. 2019. IEEE standard for safety levels with respect to human exposure to electric, magnetic, and electromagnetic fields, $0 \mathrm{~Hz}$ to $300 \mathrm{GHz}$. IEEE International Committee on Electromagnetic Safety, The Institute of Electrical and Electronics Engineers. New York, USA.

Jin YB, Choi HD, Kim BC, Pack JK, Kim N, Lee Y S. 2013. Effects of simultaneous combined exposure to CDMA and WCDMA electromagnetic fields on serum hormone levels in rats. J Rad Res 54(3):430-437.

Jung KB, Kim TH, Kim JL, Doh HJ, Chung YC, Choi JH, Pack JK. 2007. Development and validation of reverberation-chamber type whole-body exposure system for mobile-phone frequency. Electromag Bio Med 27(1):73-82.

Leduc C, Zhadobov M. 2017. Thermal model of electromagnetic skin-equivalent phantom at millimeter waves. IEEE Trans Microwave Theory Tech 65(3):1036-1045.

Kostas JG, Boverie B. 1991. Statistical model for a mode-stirred chamber. IEEE Trans Electromag Compat 33(4):366-370. 
Le Quément C, Nicolas Nicolaz C, Zhadobov M, Desmots F, Sauleau R, Aubry M, Michel D, Le Dréan Y. 2012. Whole-genome expression analysis in primary human keratinocyte cell cultures exposed to $60 \mathrm{GHz}$ radiation. Bioelectromagnetics 33(2):147-158.

Lemoine C, Besnier P, Drissi MH. 2007. Investigations of reverberation chamber measurements through high-power goodness-of-fit tests. IEEE Trans Electromag Compat 49(4):745-755.

Lemoine C, Besnier P, Drissi MH. 2008. Estimating the effective sample size to select independent measurements in a reverberation chamber. IEEE Trans Electromag Compat 50(2):227-236.

MiWaves "Beyond 2020 heterogeneous wireless network with millimeter wave small cell access and backhauling (MiWaves)". EU Project. Available from https://cordis.europa.eu/project/rcn/189113/factsheet/fr [Last accessed 13 August 2019].

MiWEBA “Millimetre-Wave Evolution for Backhaul and Access (MiWEBA)”. Available from http://www.miweba.eu [Last accessed 13 August 2019].

mmMAGIC “mm-Wave based Mobile Radio Access Network for 5G Integrated Communications (mmMAGIC)". Available from https://5g-mmmagic.eu [Last accessed 13 August 2019].

Neufeld E, Carrasco E, Murbach M, Balzano Q, Christ A, Kuster N. 2018. Theoretical and numerical assessment of maximally allowable power-density averaging area for conservative electromagnetic exposure assessment above $6 \mathrm{GHz}$. Bioelectromagnetics 39(8):617-630.

Nicolaz CN, Zhadobov M, Desmots F, Ansart A, Sauleau R, Thouroude D, Michel D, Le Dréan Y. 2009. Study of narrow band millimeter-wave potential interactions with endoplasmic reticulum stress sensor genes. Bioelectromagnetics 30(5):365-373. 
Shi J, Chakarothai J, Wang J, Wake K, Watanabe S, Fujiwara O. 2014. Quantification and verification of whole-body-average SARs in small animals exposed to electromagnetic fields inside reverberation chamber. IEICE Trans Commun E97-B(10):2184-2191.

Shi J, Chakarothai J, Wang J, Wake K, Watanabe S, Fujiwara O. 2015. Dosimetry and verification for 6-GHz whole-body non-constraint exposure of rats using reverberation chamber. IEICE Trans Commun E98-B(7):1164-1172.

Orjubin G. 2007. Maximum field inside a reverberation chamber modeled by the generalized extreme value distribution. IEEE Trans Electromag Compat 49(1):104-113.

Orlacchio R, Le Page Y, Le Dréan Y, Le Guével R, Sauleau R, Alekseev S, Zhadobov M. 2019. Millimeter-wave pulsed heating in vitro: cell mortality and heat shock response. Scientific Reports (under revision).

Rojavin MA, Ziskin MC. 1998. Medical application of millimetre waves. Q J Med 91(1):57-66.

Smulders PFM. 2013. Analysis of human skin tissue by millimeter-wave reflectometry. Skin Res Technol 19(1):e209-16.

Wi-Fi Alliance (Wireless Gigabit Alliance). 2016. Available from http://www.wi-fi.org/ [Last accessed 13 August 2019]

Wissler EH. 1961. Steady-state temperature distribution in man. J App Physiol 16(4):734-740.

Wu T, Hadjem A, Wong MF, Gati A, Picon O, Wiart J. 2010. Whole-body new-born and young rats' exposure assessment in a reverberating chamber operating at 2.4 GHz. Phys Med Biol $55(6): 1619-30$.

Wu T, Rappaport TS, and Collins MC. 2015.Safe for generations to come: Considerations of safety for millimeter waves in wireless communications. IEEE Microw Mag 16(2):65-84. 
Zhadobov M, Chahat N, Sauleau R, Le Quement C, Le Dréan, Y. 2011. Millimeter-wave interactions with the human body: State of knowledge and recent advances. Int J Microwave Wireless Technol 3(02):237-247.

Zhadobov M, Alekseev SI, Le Dréan Y, Sauleau R, Fesenko EE. 2015. Millimeter waves as a source of selective heating of skin. Bioelectromagnetics 36(6):464-475.

Zhang M, Che Z, Chen J, Zhao H, Yang L, Zhong Z, Lu J. 2010. Experimental determination of thermal conductivity of water agar gel at different concentrations and temperatures. J Chem Eng Data 56(4):859-864.

Ziskin MC, Alekseev SI, Foster KR, Balzano Q. 2018. Tissue models for RF exposure evaluation at frequencies above $6 \mathrm{GHz}$. Bioelectromagnetics 39(3): 173-189. 


\section{Figure captions}

Fig. 1. 3D CAD design of the RC designed in solidworks: a) 3D view; (b) side view.

Fig. 2. Experimental set-up. A murine plastic cage is placed in the middle of the RC. It is filled with $30 \mathrm{~g}$ of bedding litter and contains five identical mice phantoms.

Fig. 3. Murine-equivalent phantom at $60 \mathrm{GHz}$.

Fig. 4. Complex permittivity of the murine skin-equivalent phantoms with $30 \%$ polyethylene powder concentration: (a) real part; (b) imaginary part. Error bars represent $\pm 12 \%$ with respect to target value of the murine skin permittivity.

Fig. 5. Average first-order autocorrelation function calculated for the transfer function $|H|$.

Fig. 6. Anderson Darling goodness-of-fit test for exponential distribution for the transfer function $|H|$.

Fig. 7. Normalized standard deviation estimated from the transfer function $|H|$. 
Fig. 8. Experimental $Q$-factor of the RC for the empty RC, RC loaded with the murine cage, $\mathrm{RC}$ loaded with the murine cage and the bedding litter, RC loaded with these elements and one phantom, RC loaded with 5 phantoms.

Fig. 9. The five considered configurations for estimation of the quality factor variability with respect to the positions of phantoms.

Fig. 10. Experimental $Q$-factor of the reverberation chamber with respect to the positions of the phantoms.

Fig. 11. Heating of the water-equivalent phantom surface recorded by the IR camera after $800 \mathrm{~s}$ of exposure. Input power of (a) $3.59 \mathrm{~W}$, (b) $2.85 \mathrm{~W}$.

Fig. 12. Measured and calculated temperature rise on the water equivalent-phantom surface for 900 s of exposure.

Fig. 13. Heating of the murine phantoms surface recorded by the IR camera after $5400 \mathrm{~s}$ of exposure for an input power of $1.14 \mathrm{~W}$. 
Fig. 14. Computed temperature distribution on a murine phantom for an input power of $1.14 \mathrm{~W}$.

Fig. 15. Computed and measured averaged temperature rise on the murine phantoms.

Fig. 16. Temperature rise on the murine-equivalent phantom with thermophysical properties of a $30 \%$ polyethylene phantom compared to murine skin thermophysical model. 


\section{Table captions}

Table 1. Composition of the murine-equivalent phantom

Table 2. Thermophysical properties of the murine-equivalent phantom, water-equivalent phantom and murine skin

Table 3. Ratio of the power dissipated in the walls, phantoms, bedding litter, and animal cage.

Table 4. Variability of heating according to uncertainties on thermophysical parameters and power density. 


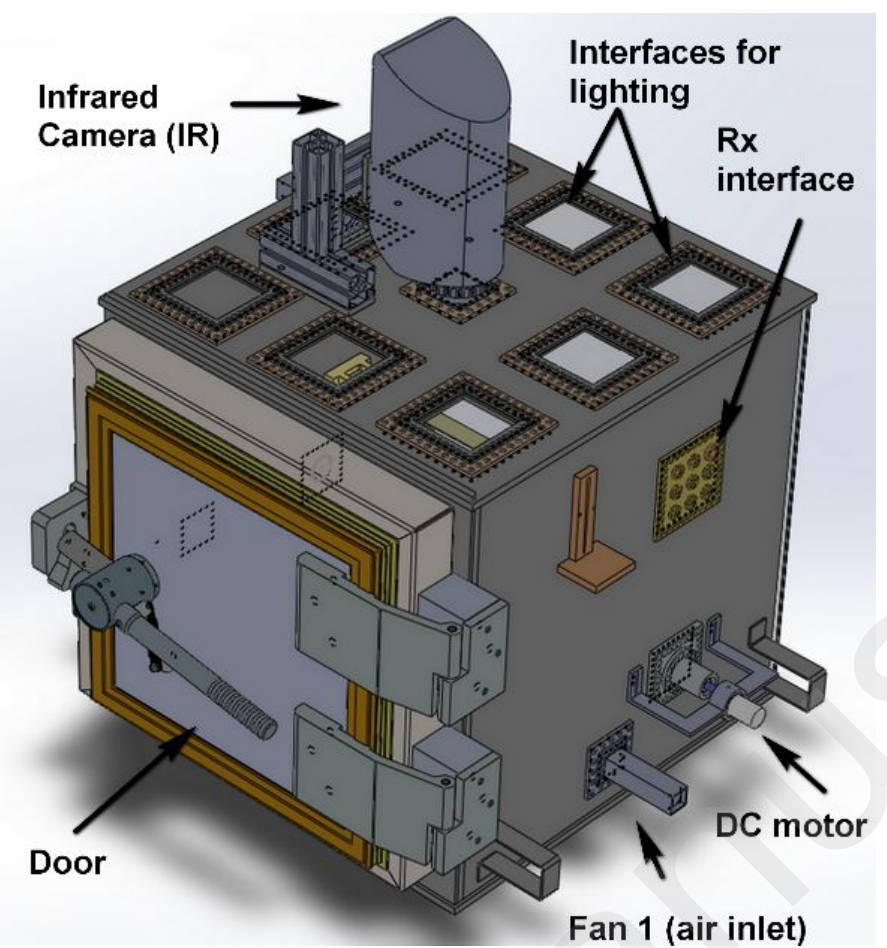

(a)

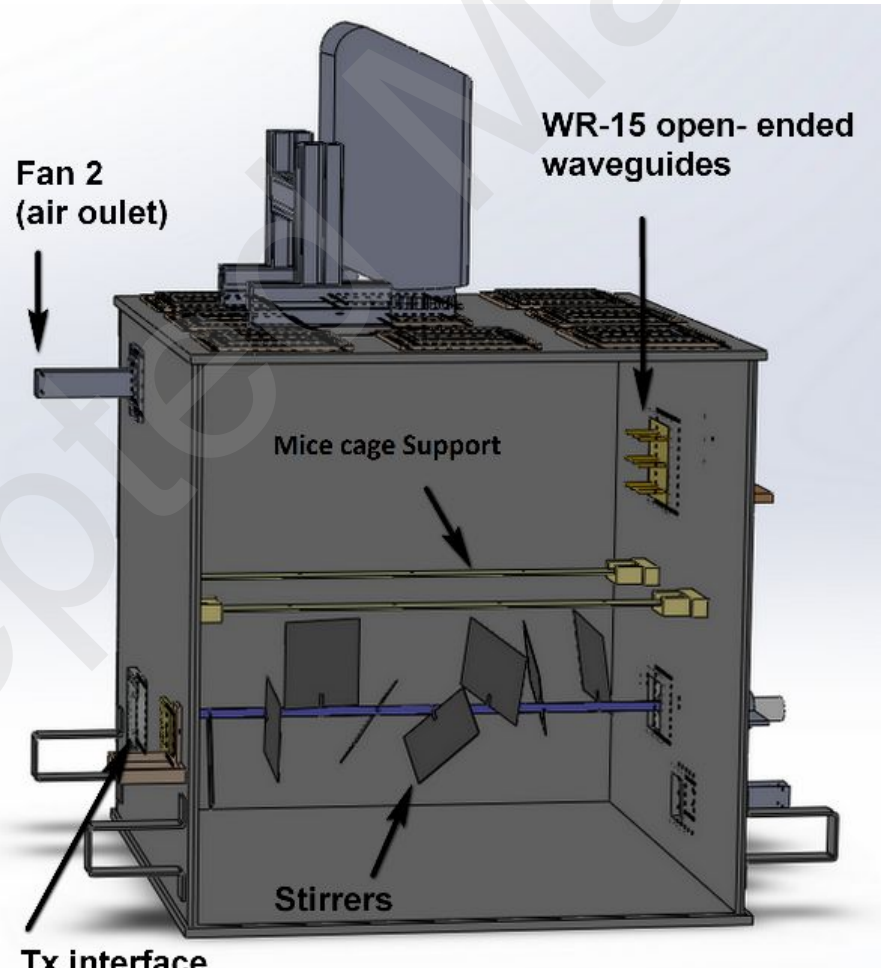

(b)

Fig. 1. 

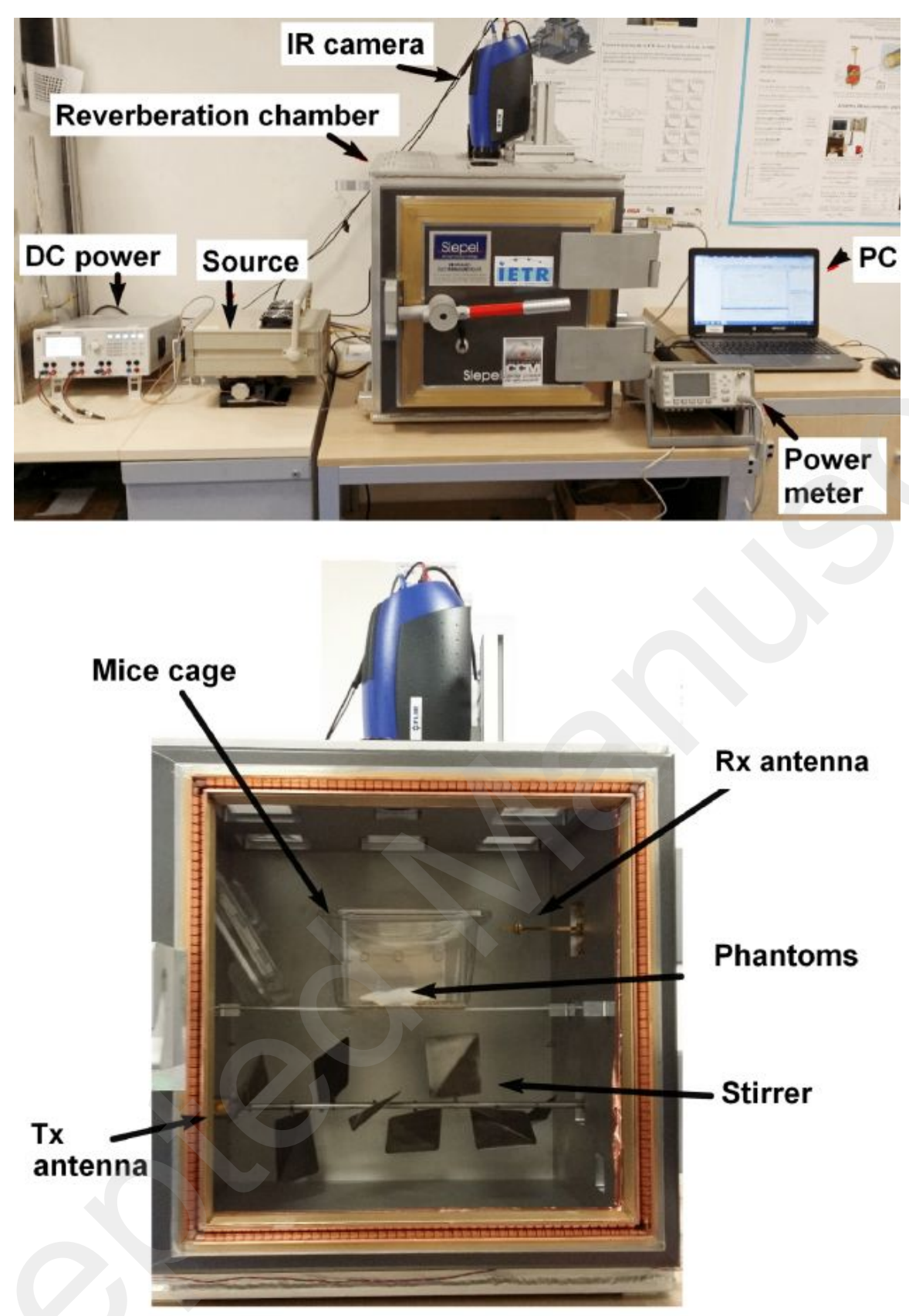

Fig. 2. 


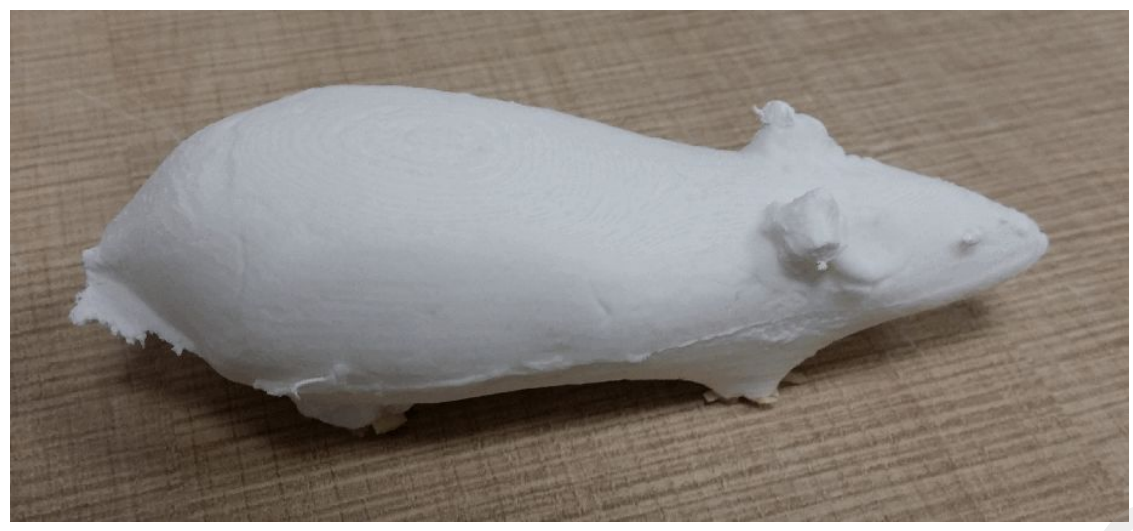

Fig. 3.

John Wiley \& Sons 


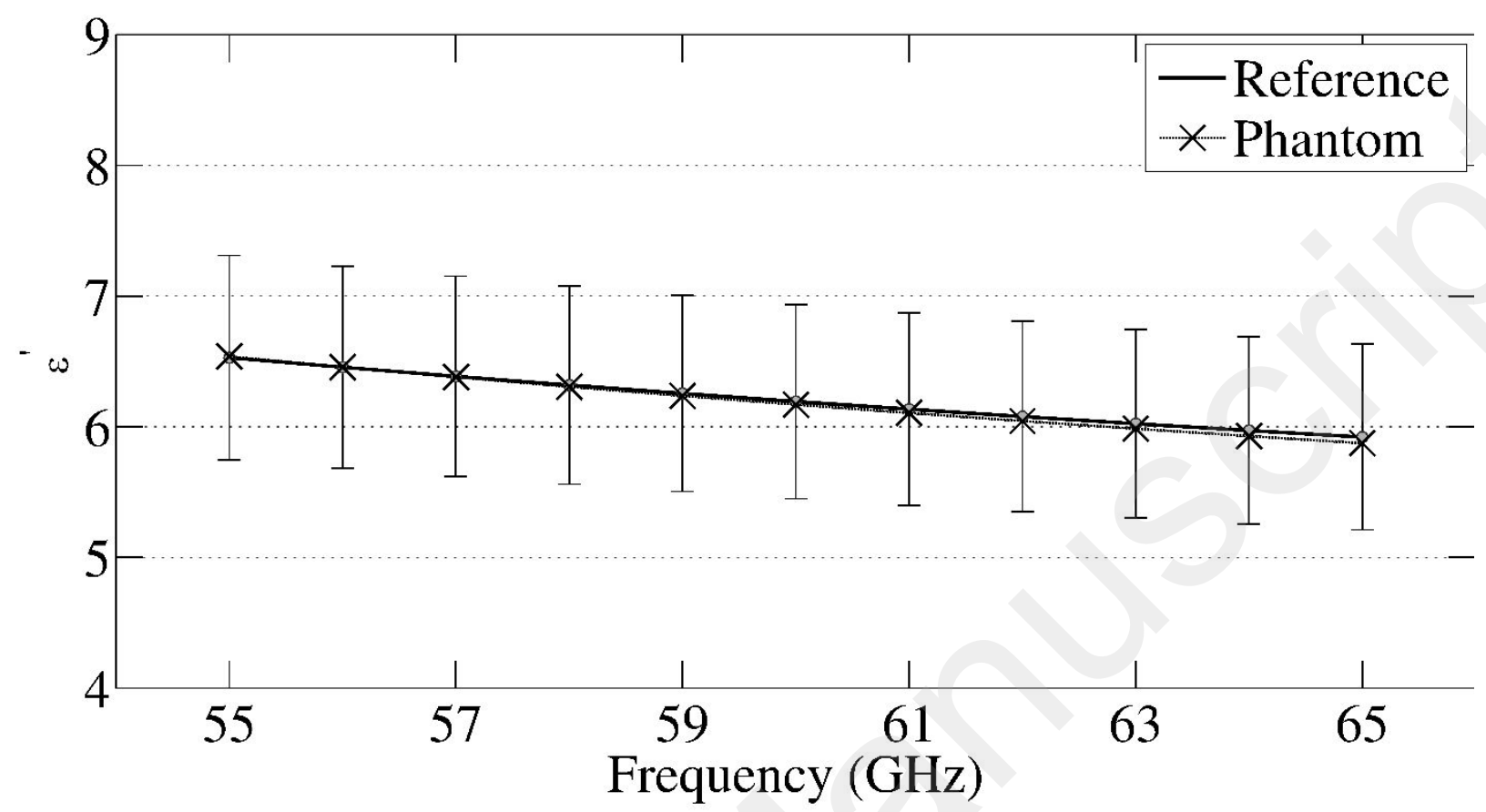

(a)

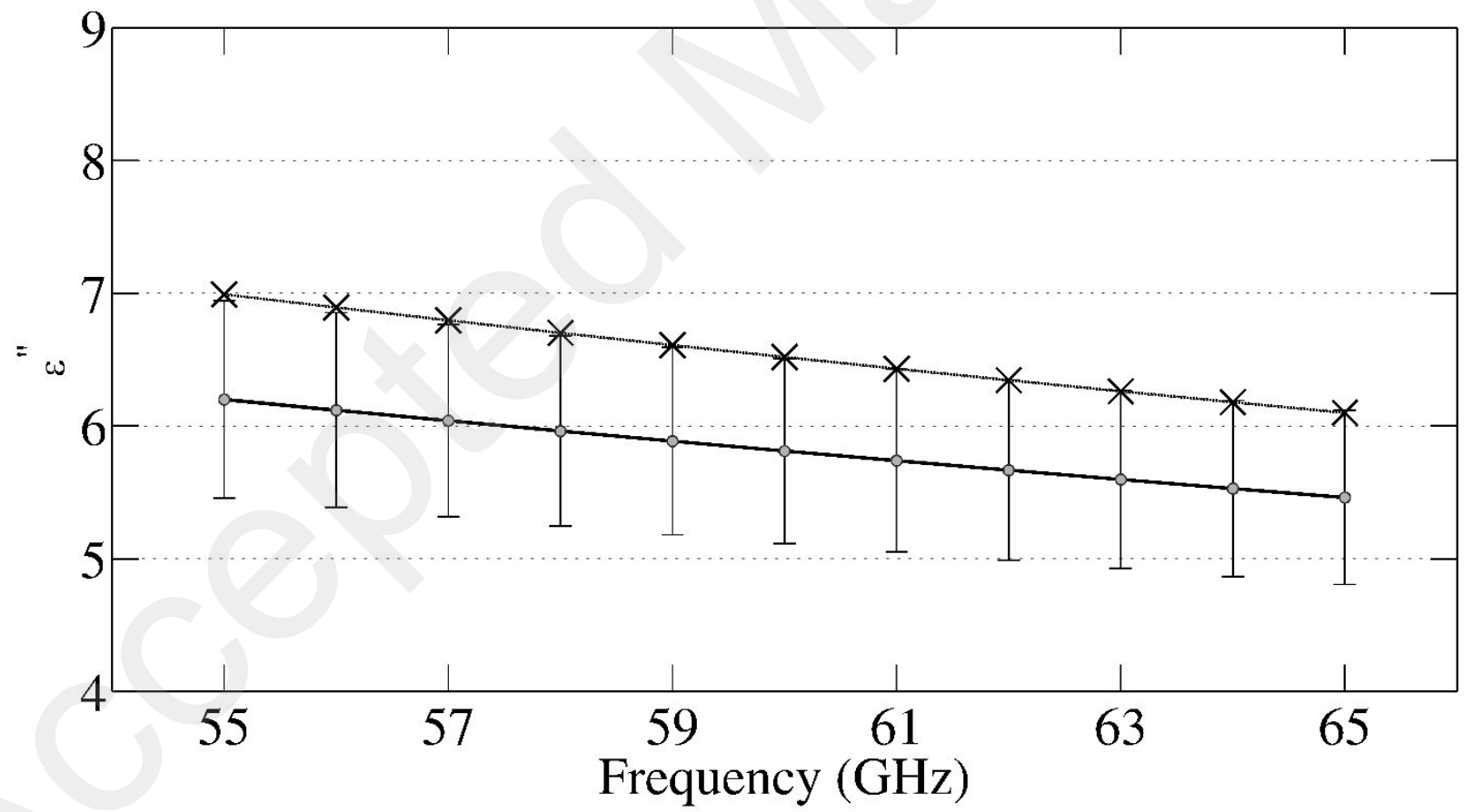

(b)

Fig. 4. 


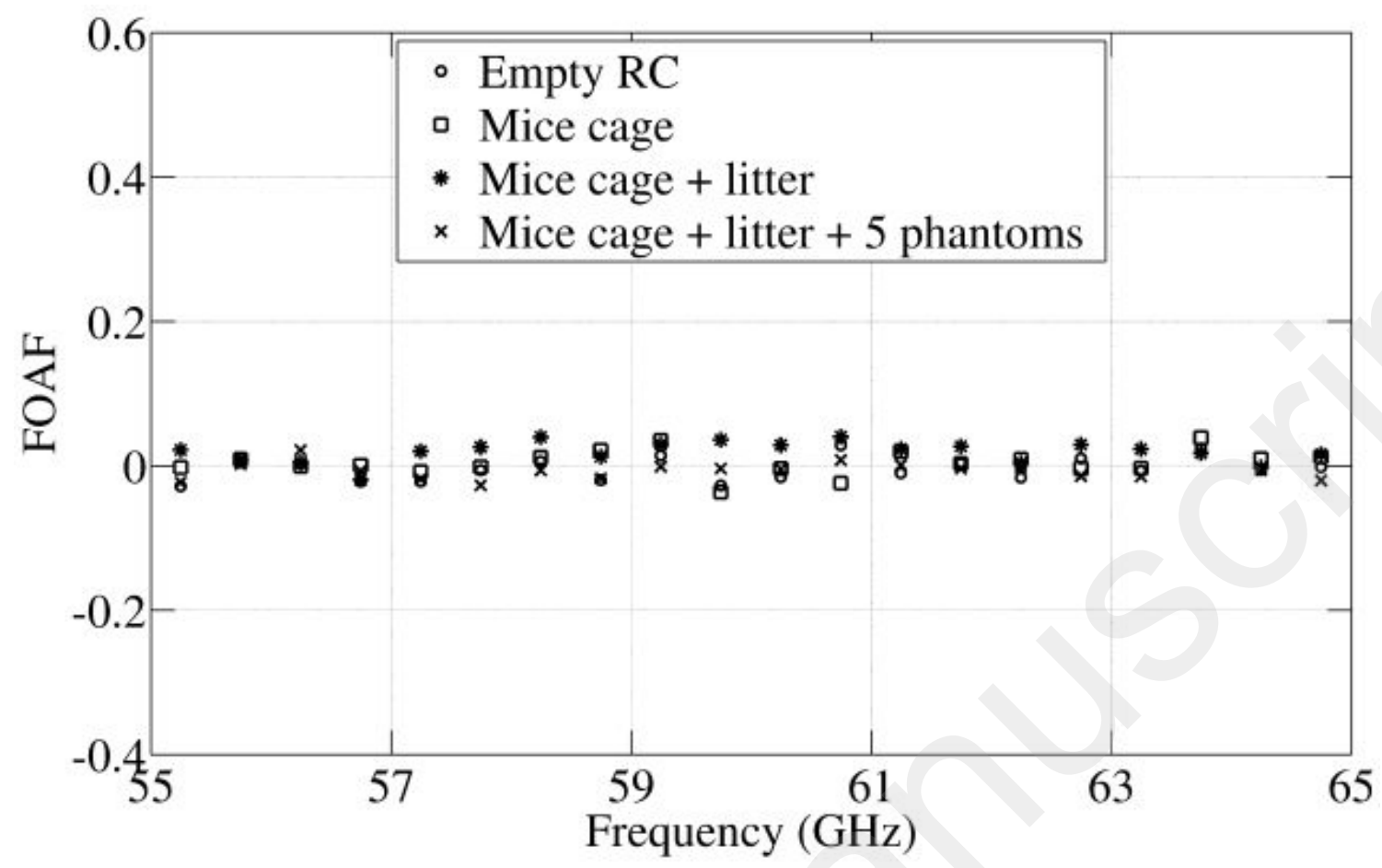

Fig. 5. 


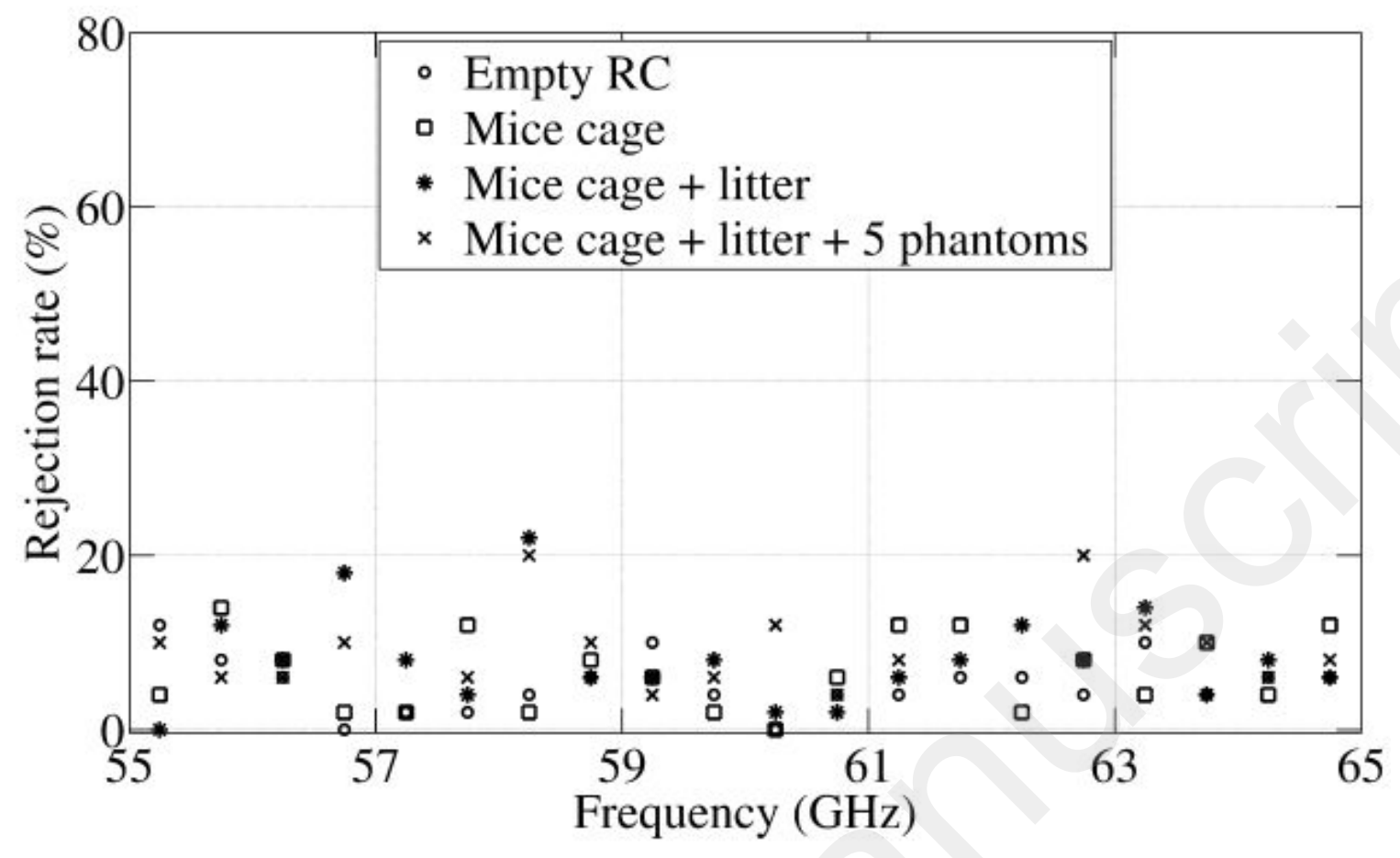

Fig. 6. 


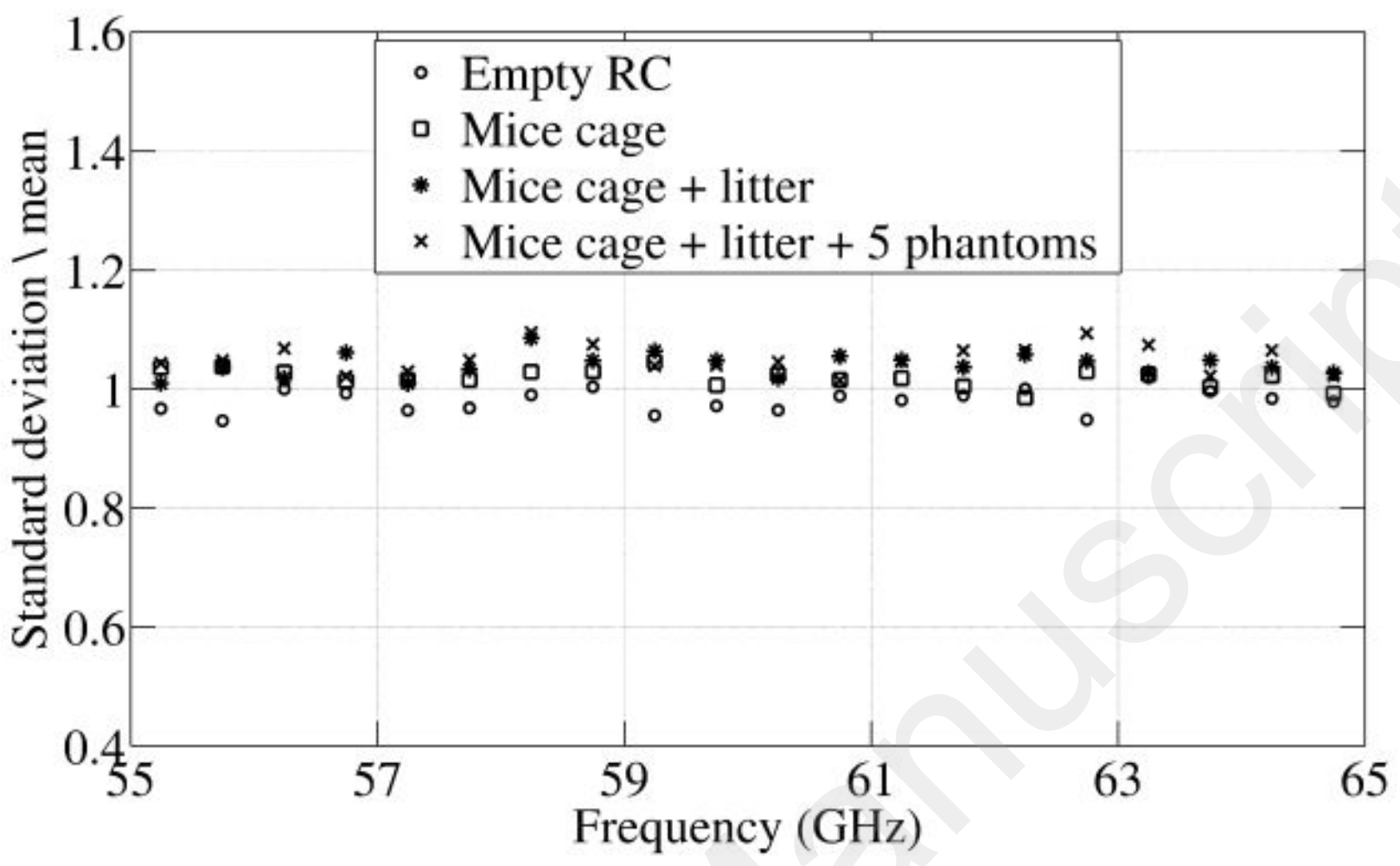

Fig. 7. 


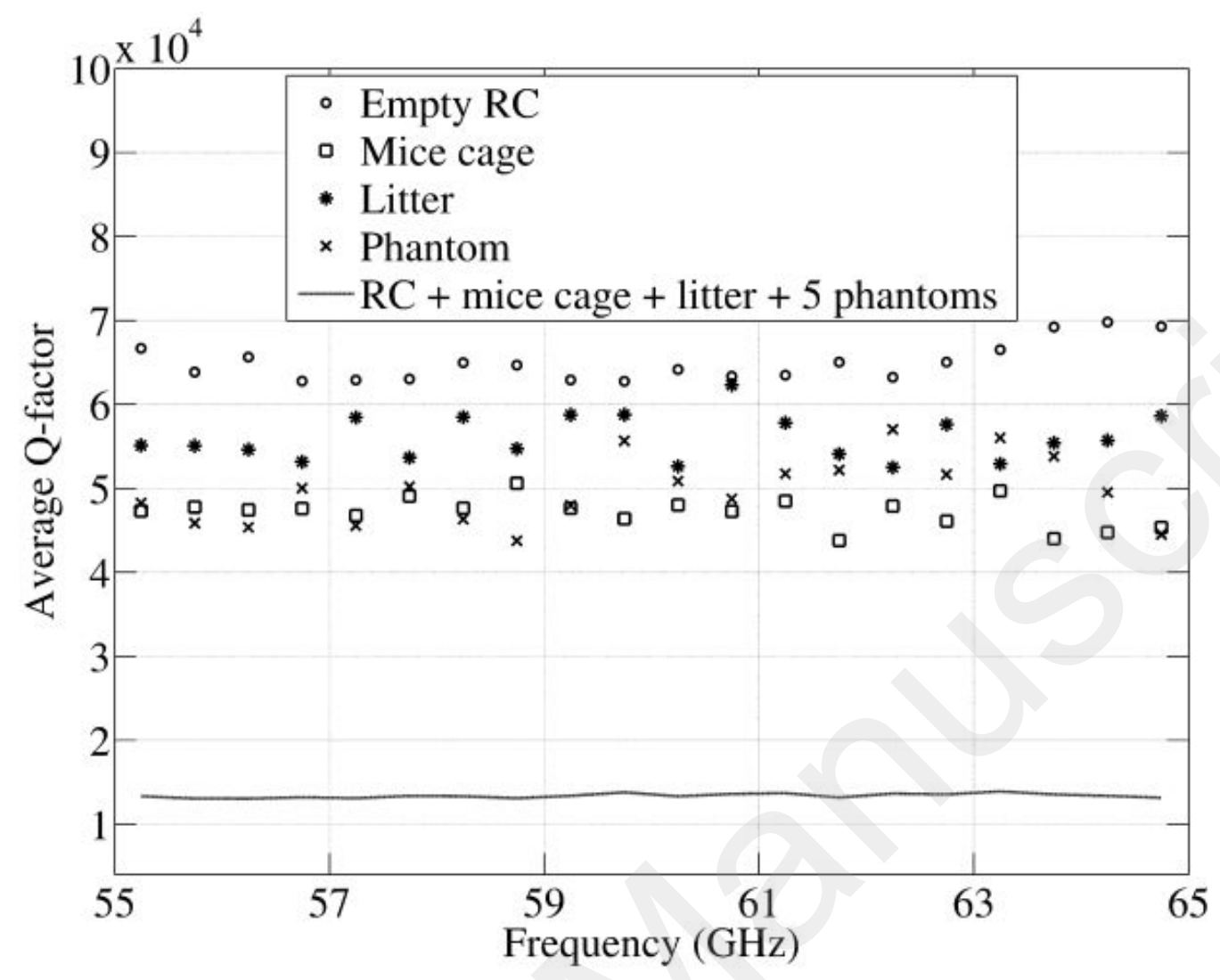

Fig. 8. 


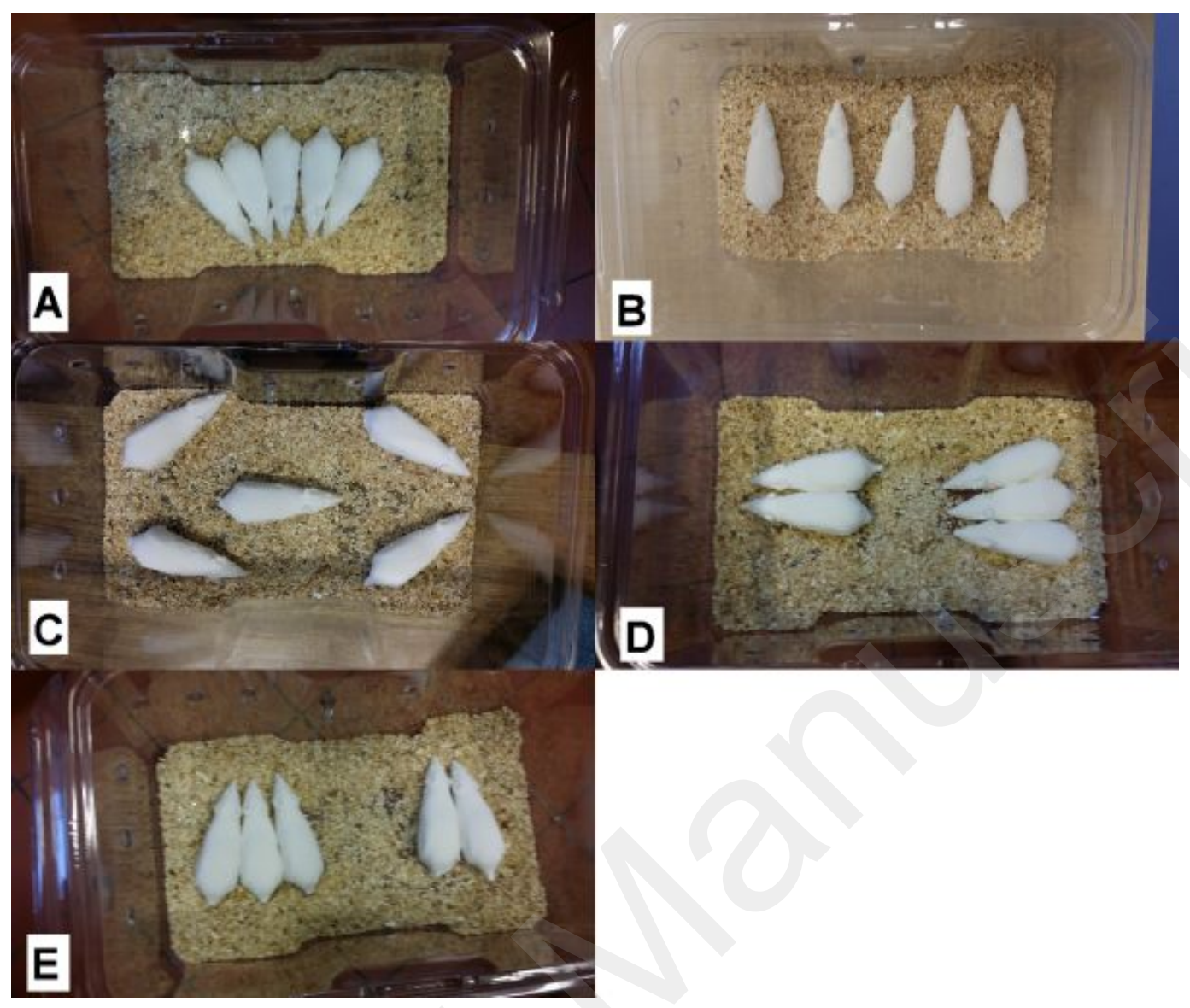

Fig. 9.

John Wiley \& Sons 


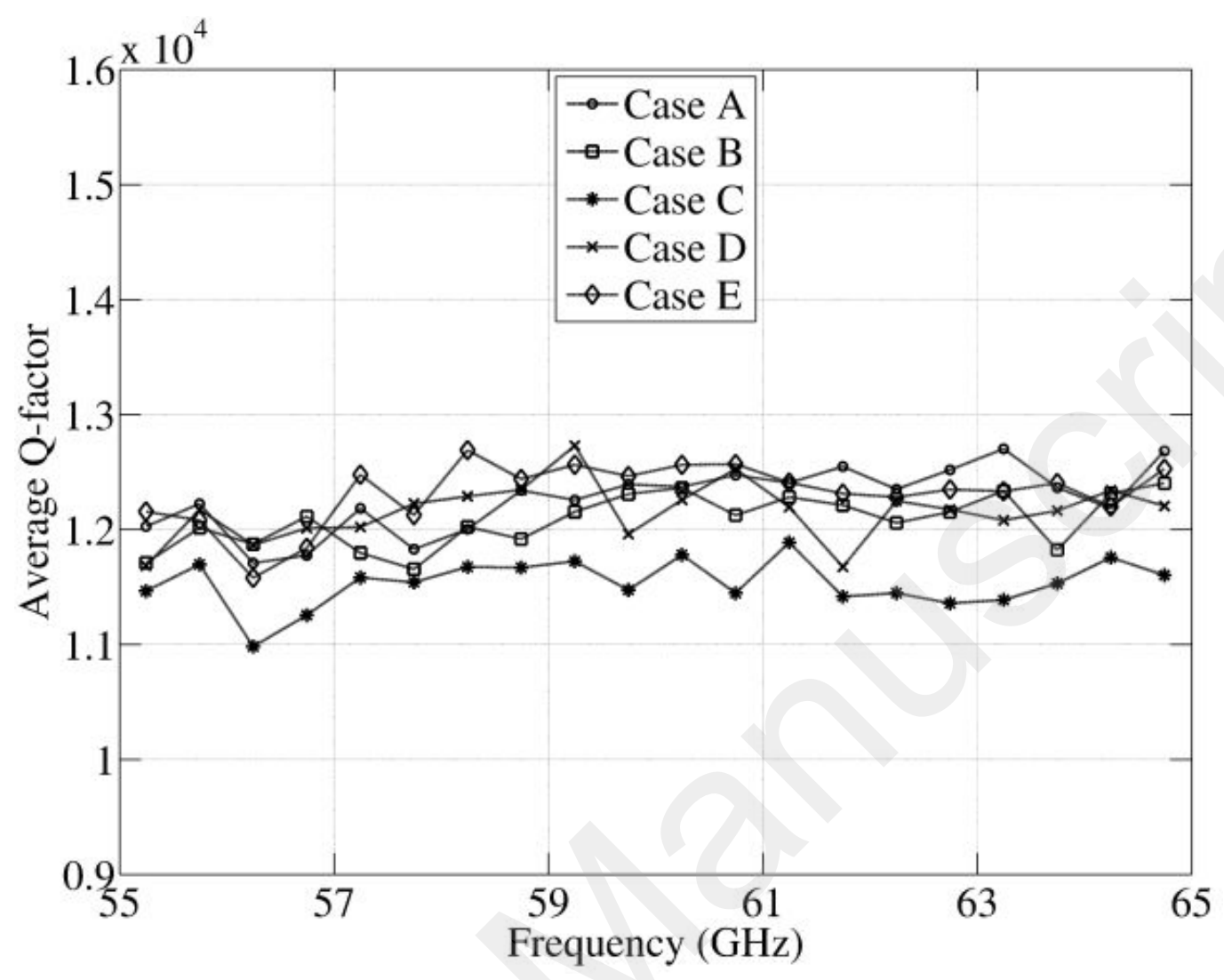

Fig. 10. 


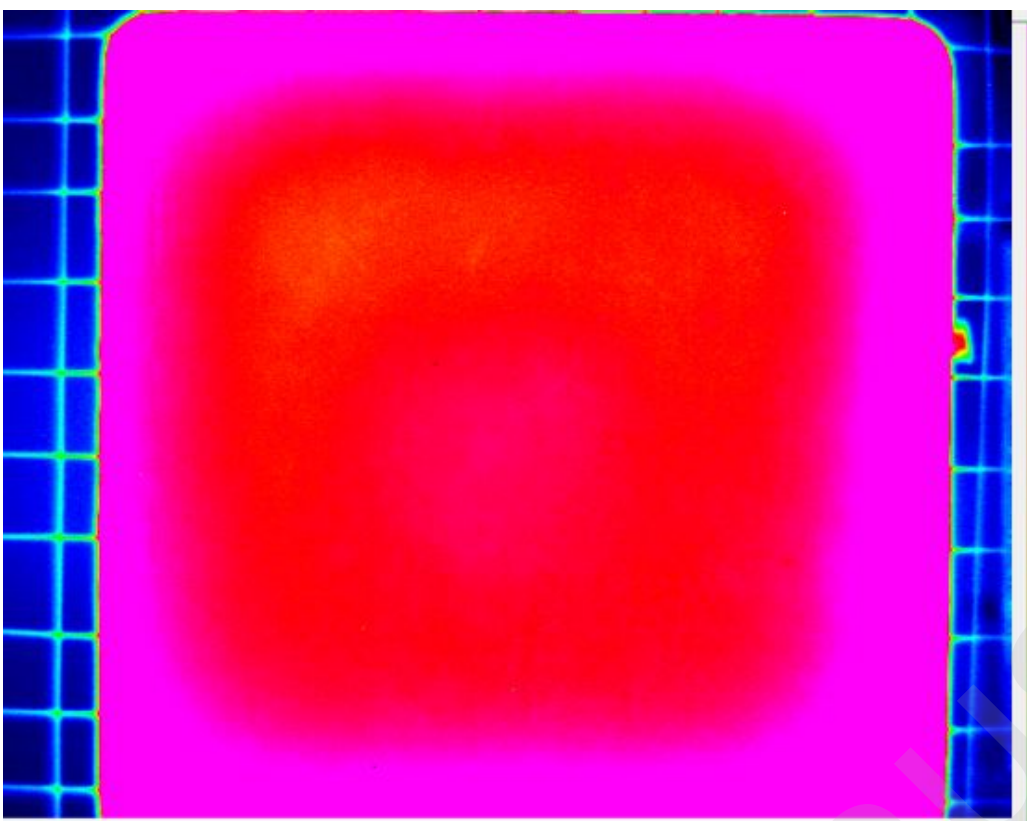

(a)

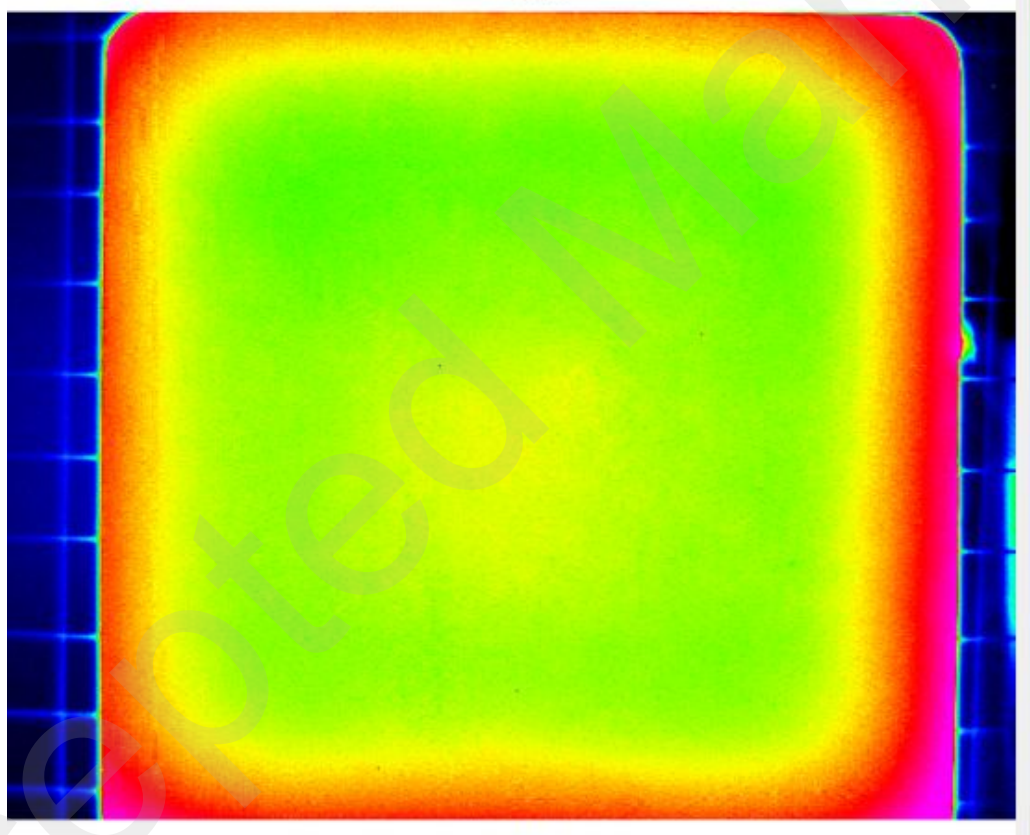

0.99

0.95

0.90

0.86

0.81

0.77

0.72

0.68

0.63

0.59

0.54

0.50

0.45

0.41

0.36

0.32

0.27

0.23

0.18

(b)

Fig. 11. 


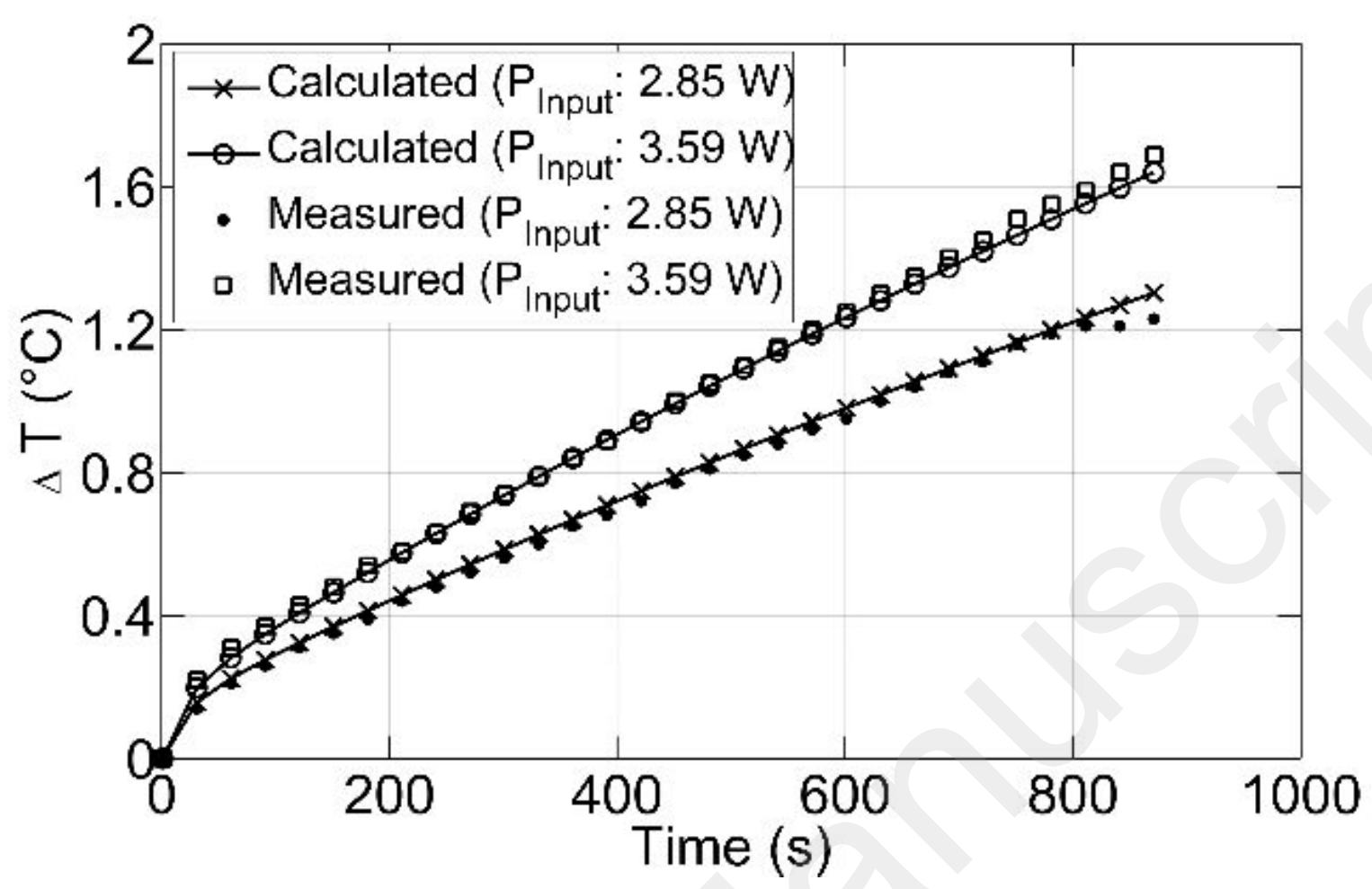

Fig. 12. 


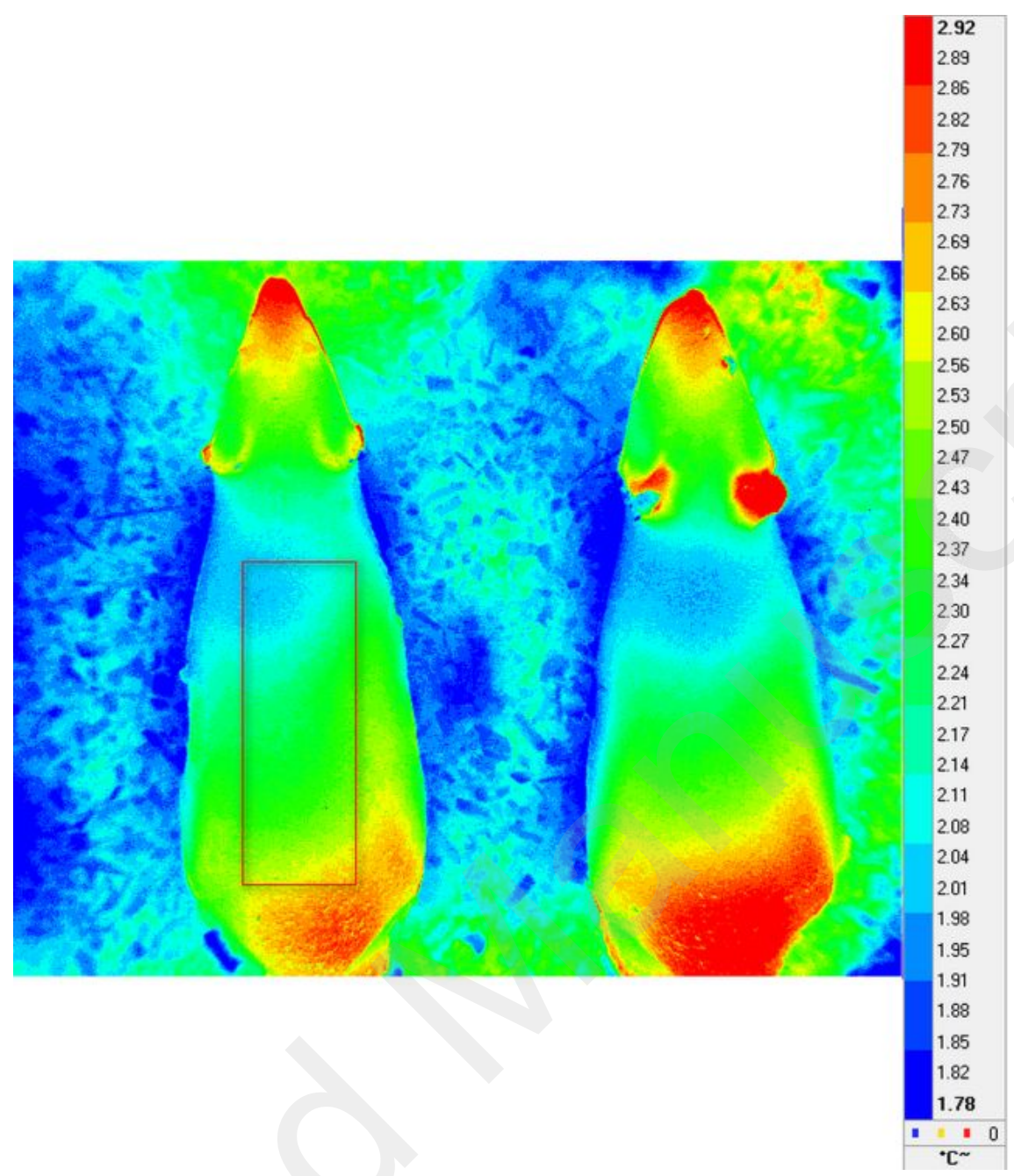

Fig. 13.

John Wiley \& Sons 


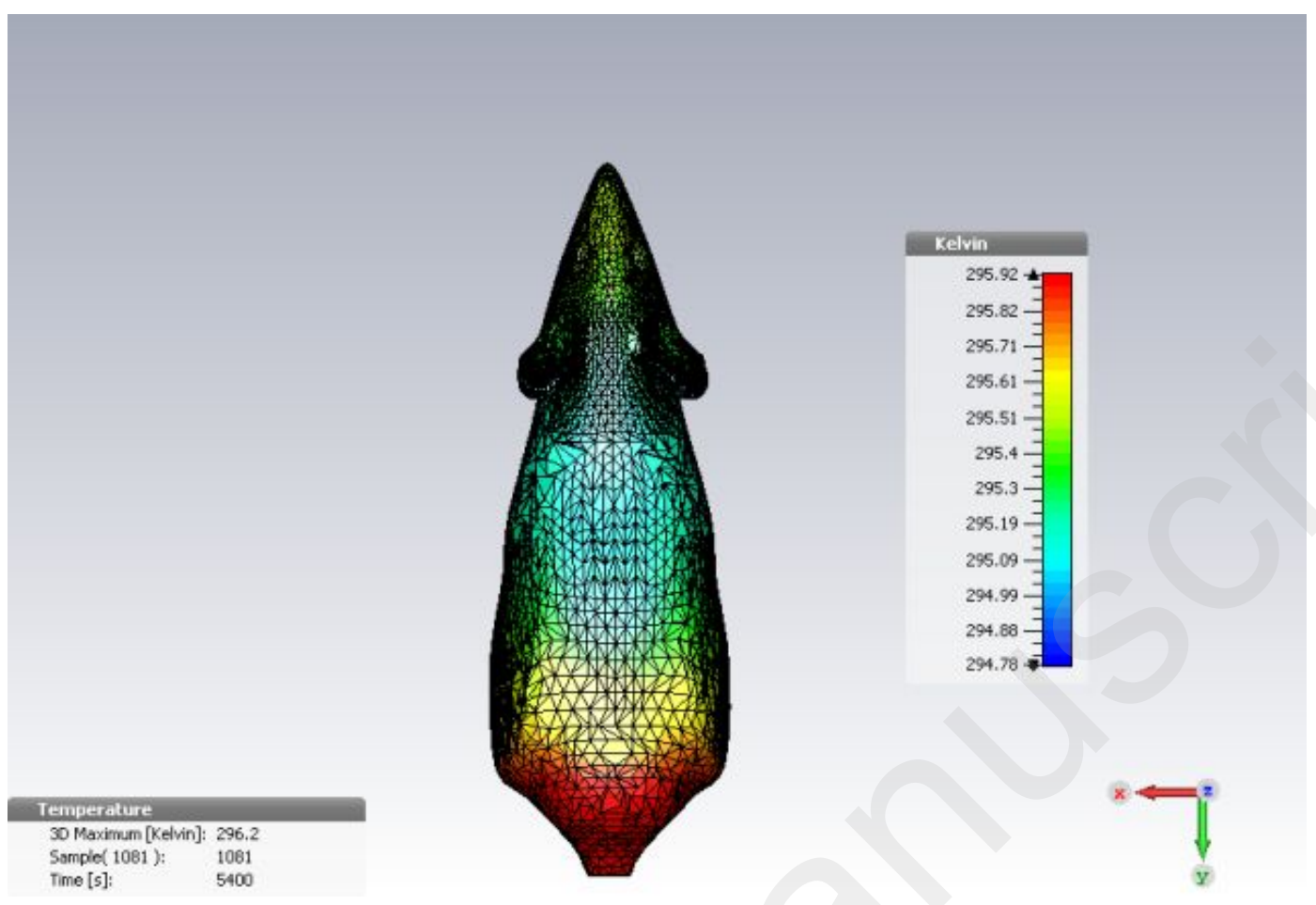

Fig. 14. 


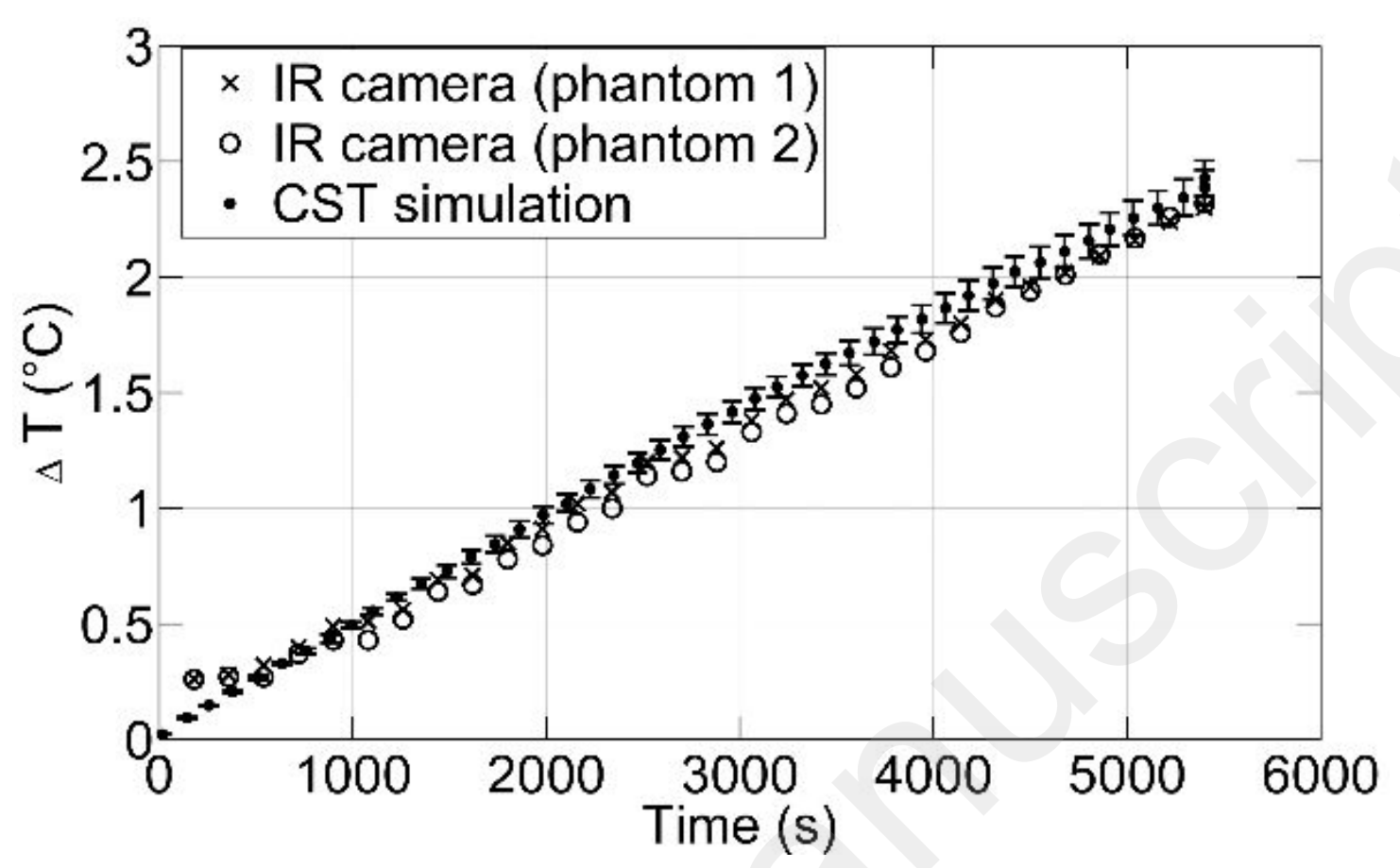

Fig. 15. 


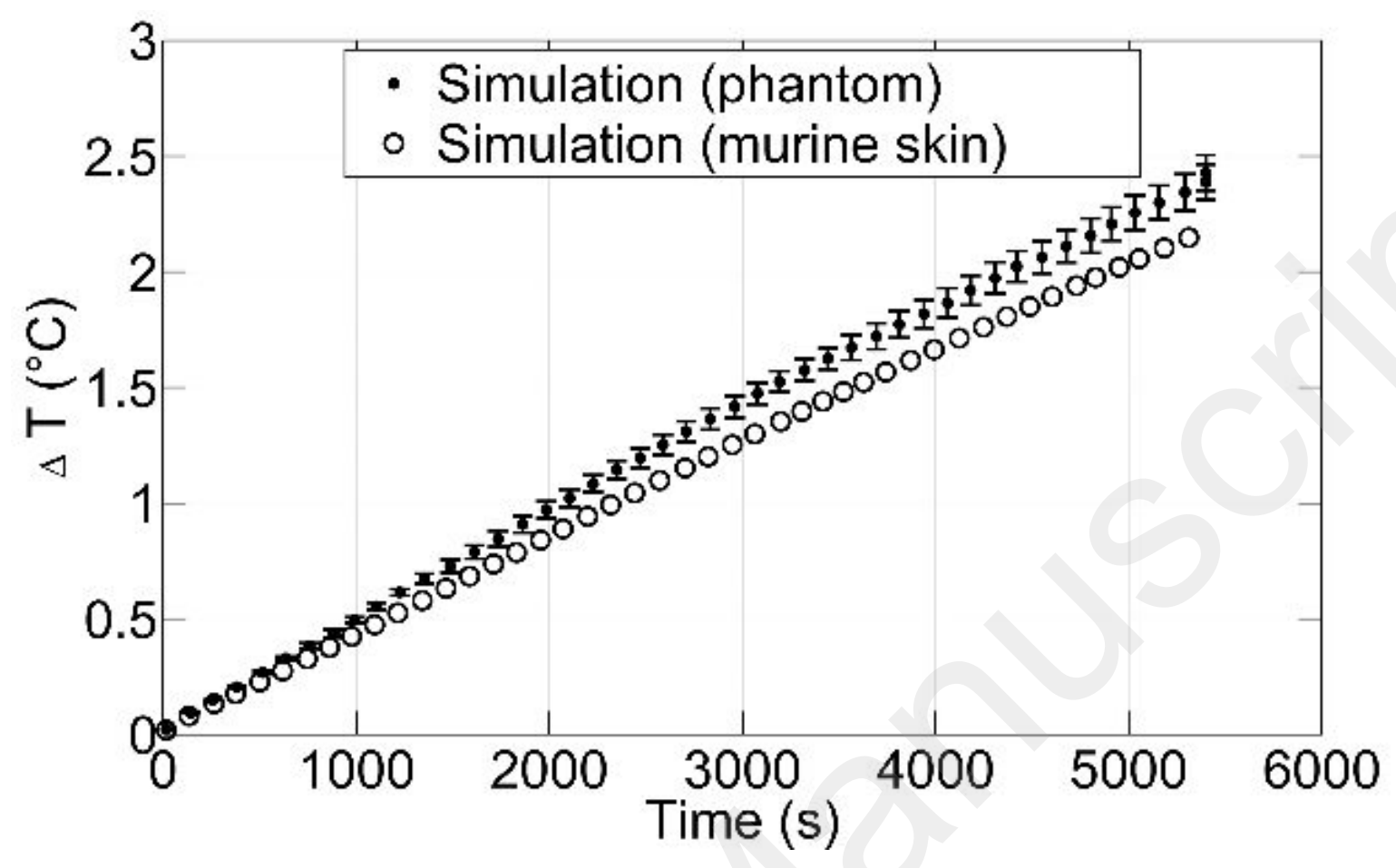

Fig. 16. 
Table 1.

\begin{tabular}{|l|c|c|}
\hline Ingredients & Mass $(\mathrm{g})$ & $\%$ in respect to water \\
\hline Distilled water & 200 & 100 \\
\hline Polyethylene powder & 60 & 30 \\
\hline Agar & 3 & 1.5 \\
\hline TX-151 & 5 & 2.5 \\
\hline
\end{tabular}


Table 2.

\begin{tabular}{|l|c|c|c|}
\hline Samples & $\begin{array}{c}k_{t} \\
{\left[\mathrm{~W} / \mathrm{m} \cdot{ }^{\circ} \mathrm{C}\right]}\end{array}$ & $\begin{array}{c}C \\
{\left[\mathrm{~J} / \mathrm{kg} \cdot{ }^{\circ} \mathrm{C}\right]}\end{array}$ & $\begin{array}{c}\rho \\
{\left[\mathrm{kg} / \mathrm{m}^{3}\right]}\end{array}$ \\
\hline Water phantom & 0.55 & $4012^{*}$ & 1000 \\
\hline Murine phantom & $0.48^{* *}$ & $3364^{* *}$ & $818^{* *}$ \\
\hline Murine skin & 0.37 & 3390 & 900 \\
\hline
\end{tabular}


Table 3.

\begin{tabular}{|l|c|c|c|c|}
\hline & $\begin{array}{c}\text { RC } \\
\text { walls }\end{array}$ & $\begin{array}{c}5 \text { murine } \\
\text { phantoms }\end{array}$ & $\begin{array}{c}\text { Bedding } \\
\text { litter }\end{array}$ & $\begin{array}{c}\text { Animal } \\
\text { cage }\end{array}$ \\
\hline Dissipated power (\%) & 20 & 27 & 24 & 28 \\
\hline
\end{tabular}


Table 4.

\begin{tabular}{|l|c|c|}
\hline Parameters & Variability $(\%)$ & $\Delta T(\%)$ \\
\hline Power density & \pm 2.8 & \pm 3.3 \\
\hline$h_{\mathrm{r}}\left[\mathrm{W} /\left(\mathrm{m}^{2} \cdot{ }^{\circ} \mathrm{C}\right)\right]$ & \pm 5 & \pm 2 \\
\hline$h_{\mathrm{c}}\left[\mathrm{W} /\left(\mathrm{m}^{2} \cdot{ }^{\circ} \mathrm{C}\right)\right]$ & \pm 14 & \pm 7.0 \\
\hline$k_{\mathrm{t}}\left[\mathrm{W} / \mathrm{m} \cdot{ }^{\circ} \mathrm{C}\right]$ & \pm 10 & \pm 1.4 \\
\hline$C\left[\mathrm{~J} / \mathrm{kg} \cdot{ }^{\circ} \mathrm{C}\right]$ & \pm 10 & \pm 9.9 \\
\hline
\end{tabular}

